\title{
Analysis on Water use Efficiency of Populus Euphratica Forest Ecosystem in Arid Area
}

\author{
Xue Lianqing \\ Hohai University \\ Fu Fangbing ( 1203413638@qq.com ) \\ Hohai University https://orcid.org/0000-0001-5298-7044 \\ Chen Xinfang \\ Hohai University \\ Liu Yuanhong \\ Hohai University \\ Han Qiang \\ Hohai University \\ Liao Shumin \\ Hohai University \\ Wei Qing \\ Hohai University
}

\section{Research Article}

Keywords: Populus euphratica forest ecosystem, Eddy covariance, Water use efficiency, Gross primary productivity, Net ecosystem productivity, Evapotranspiration

Posted Date: April 19th, 2021

DOI: https://doi.org/10.21203/rs.3.rs-419407/v1

License: (c) (i) This work is licensed under a Creative Commons Attribution 4.0 International License.

Read Full License 


\section{Analysis on water use efficiency of Populus euphratica forest}

\section{2 ecosystem in arid area}

3 Lianqing Xue ${ }^{\mathrm{a}, \mathrm{b}, \mathrm{c}}$, Fangbing Fu ${ }^{\mathrm{a}, *}$, Xinfang Chen ${ }^{\mathrm{a}}$, Yuanhong Liu ${ }^{\mathrm{a}}$, Qiang Han ${ }^{\mathrm{a}}$,

4 Shumin Liao ${ }^{\text {a }}$, Qing Wei ${ }^{\mathrm{a}}$

$5{ }^{a}$ College of Hydrology and Water Resources, Hohai University, Nanjing 210098, P. R.

6 China

$7 \quad{ }^{\mathrm{b}}$ Hohai University Wentian College, Maanshan 243000, P. R. China

$8 \quad$ 'Shihezi University, Shihezi 832009, P. R. China

\section{Abstract}

10 Water use efficiency (WUE, the ratio of gross primary productivity (GPP) to 11 evapotranspiration (ET)) reflects the coupled relationship between water loss and carbon gain in the process of plant photosynthetic carbon assimilation. As a dominant tree species in arid area, Populus euphratica plays an important ecological role in

14 slowing desertification. Here, continuous observations of carbon, water and energy 15 fluxes were carried out in Populus euphratica forest with eddy covariance (EC) 16 technique in 2018. We systematically explained the variation characteristics of energy

17 fluxes and WUE at different time scales, and explored the main controlling factors of 18 WUE in drought-stressed environment based on the synchronous meteorological data. 19 Results showed that the carbon exchange of the Populus euphratica forest ecosystem occurred mainly during the growing seasons (April-October). During this period, the

21 entire ecosystem appeared as a carbon sink with the potential to sequester atmospheric 22 carbon dioxide. The average daily WUE was $2.2 \mathrm{~g} \mathrm{C} / \mathrm{kg} \mathrm{H}_{2} \mathrm{O}$, which was lower than 23 other temperate forests $\left(2.57-6.07 \mathrm{~g} \mathrm{C} / \mathrm{kg} \mathrm{H}_{2} \mathrm{O}\right)$ but higher than grassland, wetland 24 and cropland. We also concluded that an increase in carbon dioxide concentration $25\left(\mathrm{CCO}_{2}\right)$ and air relative humidity $(\mathrm{RH})$ could promote the increase of WUE. 26 Nevertheless, WUE was negatively correlated with air temperature (Ta), 
27 photosynthetically active radiation (PAR), and normalized difference vegetation index 28 (NDVI). Additionally, WUE increased under moderate soil water content (SWC), but decreased due to the continuously rising SWC. WUE was more strongly affected by factors affecting water consumption than carbon uptake. Under the conditions of high temperature, strong radiation and low humidity in the summer, the growth rate of ET was much larger than that of GPP. This study not only contributes to our understanding of the carbon, water and energy dynamics of the Populus euphratica forest ecosystem but also provides an important reference for ecological conservation and ecological restoration in arid regions.

\section{Keywords}

Populus euphratica forest ecosystem; Eddy covariance; Water use efficiency; Gross primary productivity; Net ecosystem productivity; Evapotranspiration

\section{Introduction}

As global warming intensifies, climate change and its impact on terrestrial ecosystems is receiving increasing attention. Carbon and water cycles are key processes for maintaining nutritional state and energy balance of ecosystems, which are more deeply affected by climate change (Seddon et al., 2016). The development and maturity of eddy covariance (EC) technique enables long-term and continuous measurement of carbon, water and energy exchanges between land and atmosphere (Amiro et al., 2006; Yu et al., 2006). The global FLUXNET is conducting continuous observations of the carbon, water and energy exchange processes of terrestrial ecosystems. But there are fewer EC sites for arid area than the southern wet area (Kim et al., 2013). While water is the principal limiting factor in arid area, controlling plant growth and vegetation succession. Better insight into the relationship between limited water resources and ecosystem water use efficiency (WUE) would enhance our understanding of plantation-ecosystem processes, services and feedbacks to the regional climate system (Tong et al., 2014). 
In the terrestrial ecosystem, carbon and water cycles closely couple because they both exchange between biosphere and atmosphere via the same pathway, namely the stomata (Yu et al., 2008). Plant photosynthesis absorbs $\mathrm{CO}_{2}$ along with water loss to regulate the carbon-water balance between ecosystems and the atmosphere (Mammarella et al., 2015). In the same sense, WUE reflects the magnitude of fixed $\mathrm{CO}_{2}$ when plants consume unit mass of water, and reveals the exchange law of $\mathrm{CO}_{2}$ and water vapor fluxes in ecosystems and their coupling cyclic relationship (Hui et al., 2001). WUE refers to the ratio of ecosystem carbon flux to water vapor flux. This concept has been extensively used in agronomy, plant physiology and ecology since its introduction (Jin et al., 2017). Initially, studies of WUE were confined to the leaf physiological or individual levels, with the aim of breeding good crops or directing field management (Keenan et al., 2013). Later, ecologists explored the mechanism of biological invasion and plant adaptation strategies to the environment by studying the WUE (Xu et al., 2004). In recent years, as global climate change issues become more prominent, more perspectives have been directed to native ecosystems such as grasslands and forests. Research scales have also risen to canopy, ecosystems and landscape levels (Zhao et al., 2007). Many scholars have carried out a large number of 71 WUE researches, involving different spatial scales such as tissues, populations, communities, and regions (Jassal et al., 2009; Skubel et al., 2015; Oquist et al., 2017; Stephens et al., 2018). These studies serve to reveal the interactions of water-carbon cycles, to predict impacts of global change on ecosystem functions (Jin et al., 2017). In the context of climate change, the response of the carbon cycle and water cycle in the arid region of China has attracted special attention (Ma et al., 2019). Some studies have found that drought can reduce WUE (Brümmer et al., 2012; Zhang et al., 2014), 78 while others have found that it can increase WUE (Ponton et al., 2006; Linderson et 79 al., 2012). However, these studies still lack a scientific understanding of the 80 physiological mechanism of the seasonal change of ecosystem WUE during drought 81 period. Studies have shown that the duration of drought also has different effects on 
WUE (Hui et al., 2001). This is because the impact of drought on ET is long-term, including vegetation growth season and subsequent non-growth season (Yu et al., 2008; Govind et al., 2011). Obviously, the ecosystem WUE in arid areas needs more in-depth research.

In arid region, Populus euphratica plays an important role in the ecological protection of arid regions, which can prevent wind and immobilize sand effectively (Chen et al., 2017). In the world, 54\% of Populus euphratica is distributed in China. While in China, more than $90 \%$ of Populus euphratica resources are concentrated in Xinjiang. Currently, the research of carbon and water cycles on Populus euphratica forest ecosystem mainly focuses on biomass or a certain component of Populus euphratica, such as forest soil, plant body or leaf. In addition, the observation time is short and discontinuous. Therefore, the process and mechanism of carbon, water and energy exchanges cannot be seriously studied. Based on the aforementioned scholars' research, we used the $\mathrm{CO}_{2}$ flux $(\mathrm{Fc})$ to directly estimate the respiration, and solved the problem that the respiration is difficult to be measured. In addition, we compared WUE in the major types of ecosystems around the world. This is an important reference for analyzing whether a Populus euphratica ecosystem is carbon source or a carbon sink, and predicting the impact of global changes and human disturbances on forest carbon budgets.

This study took the Populus euphratica community in the lower reaches of the Tarim River as the research object. Continuous observation of $\mathrm{CO}_{2}$, water and energy exchanges was carried out using EC technique. The main objectives were (1) to clarify the daily and seasonal variations of carbon, water and energy fluxes caused by diurnal cycles and seasonal changes, (2) to study the carbon exchange process and carbon source/sink changes, (3) to determine the change law of ecosystem WUE, and analyze the influence mechanism of environmental factors on WUE by combining hydrometeorological elements. 


\section{Methodology}

110 2.1. Study site

111 The study site is located in Ruoqiang County $\left(40^{\circ} 27^{\prime} 10.2^{\prime \prime} \mathrm{N}, 87^{\circ} 54^{\prime} 02.9^{\prime \prime} \mathrm{E}, 842 \mathrm{~m}\right.$

112 above mean sea level, AMSL), Xinjiang, China. The EC station is located in the

113 Populus euphratica forest on the bank of the Tarim River (Fig. 1). The climate in this

114 region is temperate continental climate with annual precipitation between $27-58 \mathrm{~mm}$.

115 The annual potential evaporation amounts to $2671-2902 \mathrm{~mm}$. The temperature in

116 January and July is $-14.9^{\circ} \mathrm{C}$ and $33.6^{\circ} \mathrm{C}$, respectively. Annual sunshine hours are

117 3082.7-3121.3h (Wang and Guo, 2018). The water table is roughly between 2.8 and

$1184.5 \mathrm{~m}$. The soil is dominated by sand $(0-100 \mathrm{~cm}$ depth $)$ and sandy loam soil

119 (100-200cm depth). The zonal vegetation in this area is temperate semi-arbor desert.

120 Due to the accumulation of river water and groundwater, the floodplain develops a

121 certain area of non-zonal meadow vegetation, forming arid riparian forest composed

122 of trees, shrubs and herbaceous plants. Trees and shrubs are distributed along the river,

123 and herbaceous plants are aggregated in the shrub community. Main dominant plants

124 are Populus euphratica (the only group of trees), Tamarix, Karelinia caspica,

125 Halimodendron halodendron and other shrubs. Average height of Populus euphratica

126 is $6-14 \mathrm{~m}$, and the average forest age is about $50 \mathrm{a}$. 


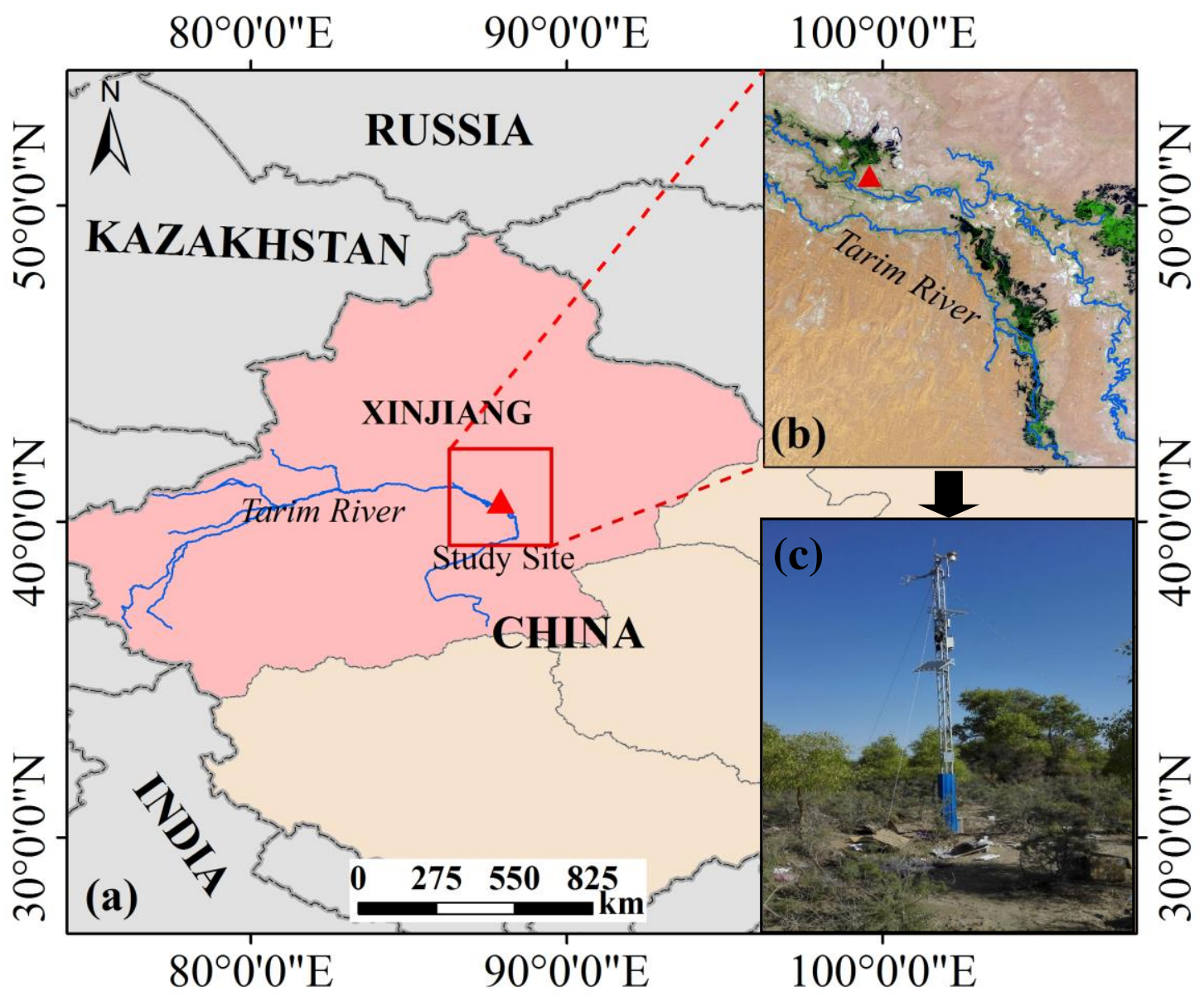

128 Fig. 1. Location of the study area and images of the observation instruments. (a) Geographical location of the 129 study site (red triangle), (b) remote sensing image of the study site and (c) erection of experimental instruments.

\subsection{Data collection and processing}

131 Water vapor and $\mathrm{CO}_{2}$ fluxes were measured at a height of $15 \mathrm{~m}$ above the ground 132 surface by an eddy covariance (EC) system consisting of an open-path infrared gas 133 analyzer (EC150) and a three-dimensional sonic anemometer (CSAT3). The EC 134 system performed real-time monitoring for $24 \mathrm{~h}$ and automatically acquired raw data 135 at a frequency of $10 \mathrm{~Hz}$. It was further equipped with meteorological element 136 monitoring sensors, including air temperature and humidity sensor (HMP155A),

137 four-component radiometer (NR01), rain gauge (TE525MM), soil heat flux sensor 138 (HFP01), photosynthetically active radiation sensor (LI190R) and soil moisture meter 139 (SDI-12). The soil moisture meter (SDI-12) monitored the soil water content (SWC) 140 at $20 \mathrm{~cm}, 40 \mathrm{~cm}$ and $60 \mathrm{~cm}$ below the surface. We used $\mathrm{SWC}$ data at $20 \mathrm{~cm}$ for 141 calculation in this paper. 
The datalogger (CR3000) collected horizontal wind speed (u, v), vertical wind

143 speed (w), Supersonic temperature (Ts), $\mathrm{H}_{2} \mathrm{O}$ concentration (q) and $\mathrm{CO}_{2}$ concentration

$144\left(\mathrm{CCO}_{2}\right)$ at the sensor height. The final flux data, including $\mathrm{CO}_{2}$ flux $(\mathrm{Fc})$, net radiation $145(\mathrm{RN})$, latent heat flux (LE), sensible heat flux $(\mathrm{H})$ and soil heat flux $(\mathrm{G})$ were

146 calculated and recorded by CR3000 at a frequency of $30 \mathrm{~min}$. In the flux calculation

147 process, double rotation, humidity correction and WPL density adjustment were 148 performed (Foken et al., 2004). The stationary, integral turbulence characteristics of

149 each 30 min flux data were calculated to filter out the periods of poor turbulent 150 development (Zhao and Liu, 2018).

151 Due to the adverse weather, the flux data inevitably had outliers and missing values.

152 Two methods were used to interpolate the missing and culled fluxes data: (1) Mean

153 diurnal variation method for gaps less than 7 days: missing values can be replaced by

154 the average of adjacent days in the same time. (2) Nonlinear regression method for 155 gaps more than 7 days: the principle of this method is to establish a regression 156 relationship between environmental factors and fluxes using observation data, and 157 then use the regression function to estimate the missing data.

158 2.3. Energy balance closure

159 Energy balance closure is an indicator of flux data quality assessment (Meyers and

160 Hollinger, 2004). Conventional methods for evaluating energy closure are: ordinary

161 least squares (OLS) linear regression, reduced major axis (RMA) linear regression, 162 energy balance ratio (EBR), and energy balance relative residual (Yang et al., 2018).

163 Among them, the EBR is the most widely used method for analyzing the energy 164 closure.

165 According to the first law of thermodynamics, the surface energy balance equation 166 can be described by the following formula:

$167 L E+H=R N-G-S-Q$

168 where $L E$ is the latent heat flux, $H$ is the sensible heat flux, $R N$ is the net radiation, $169 G$ is the soil heat flux, $S$ is the heat stored in the canopy, and $Q$ is the sum of 
170

171 values of $S$ and $Q$ are usually small (Helbig et al., 2018). So, the energy balance

172 equation can be simplified to:

$173 L E+H=R N-G$

174 In the above formula, left side of the equal sign is turbulent energy, and the right is 175 available energy. When turbulent energy $(L E+H)$ is equal to available energy $(R N-G)$,

176 it is called energy closure. This shows that the EC system can accurately observe the

177 turbulent energy. Otherwise, the EC system overestimates or underestimates the 178 turbulent energy. In this study, EBR was used to evaluate the energy closure condition, 179 defined as:

$180 \quad E B R=\frac{\sum(L E+H)}{\sum(R N-G)}$

\subsection{Calculation of WUE}

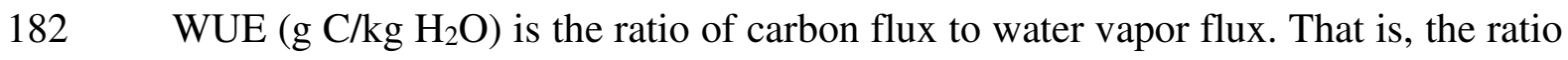
183 of the $\mathrm{CO}_{2}$ fixation to the evapotranspiration (ET) in a certain period of time. We used 184 the ratio of gross primary productivity (GPP) to ET to define ecosystem WUE, 185 expressed as:

$186 W U E=\frac{G P P}{E T}$

187 GPP was calculated with the following formulas:

$188 G P P=N E P+R_{e}=-N E E+R_{e}=-F c+R_{e}$

189 where NEP is net ecosystem productivity, which is equal to the negative value of 190 the net ecosystem $\mathrm{CO}_{2}$ exchange $(N E E) . \mathrm{CO}_{2}$ flux $(F c)$ measured by EC system is the 191 net ecosystem $\mathrm{CO}_{2}$ exchange; $\mathrm{Re}$ is total respiration of the ecosystem.

192 Re was calculated with the following formulas:

$193 R_{e}=R_{n}+R_{d}$

$194 \quad R_{n}=F_{c}($ night $)$

195

$$
R_{e}=R_{e, r e f} \cdot \exp \left(B \cdot\left(T_{a}-T_{r e f}\right)\right.
$$


where $R_{n}$ is respiration at night. The net $\mathrm{CO}_{2}$ exchange $(\mathrm{Fc}($ night $))$ can be considered as $R_{n}$ of the ecosystem (Fei et al., 2018); $R_{d}$ is respiration in daytime calculated by Vant's Hoff breathing equation (Eq. 9). Usually, fit the Vant's Hoff

199 breathing equation by relationship between $F c(n i g h t)$ and air temperature (Ta). Then 200 calculate $R d ; R_{e, r e f}$ is the respiration at the reference temperature, $T_{r e f}$ is the reference 201 temperature and $B$ is a constant. In this paper, $R_{e, r e f}=0.73 \mathrm{umol} /\left(\mathrm{m}^{2} * \mathrm{~s}\right), T_{r e f}=2.2^{\circ} \mathrm{C}$, $202 B=0.044$. We found that the turbulence at night was weak, and the $F_{c}$ data at $30 \mathrm{~min}$ 203 frequency was noisy. Therefore, we used the average value of $F_{c}$ and $T a$ data at night 204 to study the relationship between the two. As shown in Fig. 2, the correlation coefficient $\mathrm{R}^{2}=0.61$.

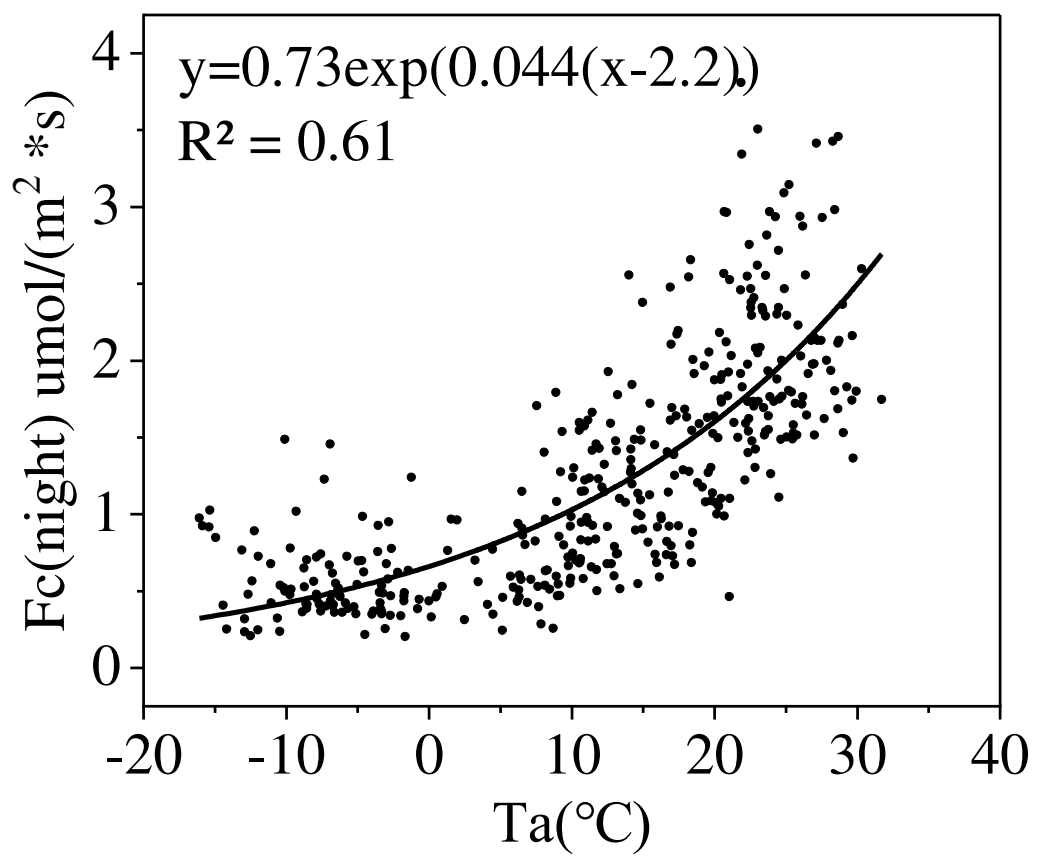

Fig. 2. The relationship between $\mathrm{CO}_{2}$ flux at night $(F c(n i g h t))$ and air temperature $(T a)$. The downward shortwave radiation (DR) is used as an indicator to distinguish daytime and nighttime. It is generally considered that when $\mathrm{DR}<1 \mathrm{~W} / \mathrm{m}^{2}$, the corresponding period is nighttime.

$210 E T$ was calculated with the following formulas:

$$
E T=\frac{L E}{\lambda}
$$

212 where $L E$ is latent heat flux measured by EC system; $\lambda$ is latent heat of vaporization 213 with a fixed value of $2.454 \times 10^{6} \mathrm{~W} \cdot \mathrm{m}^{-2} \cdot \mathrm{mm}^{-1}$. 


\section{Results}

\subsection{Dynamics of environmental factors}

216 We used auxiliary sensors in EC system to measure the environmental factors. The 217 changes of these environmental factors during the study period (2018.1.1-2018.12.31) 218 were shown in Fig. 3. The seasonal variation characteristics of Ta (Fig. 3a), PAR (Fig. 219 3b) and SWC (Fig. 3c) were basically same, with the lowest in winter at $-14.6^{\circ} \mathrm{C}$, $22095 \mathrm{umol} /\left(\mathrm{m}^{2} * \mathrm{~s}\right)$ and $6.7 \%$, and the highest in summer at $34^{\circ} \mathrm{C}, 651 \mathrm{umol} /\left(\mathrm{m}^{2} * \mathrm{~s}\right)$ and $22110.6 \%$. PAR showed low values for a few days in July due to the effects of rainy days. 222 The amount of soil water replenished by rainfall was expected to be very limited since 223 precipitation in the study site was scarce. There were two reasons for the high SWC in 224 summer. One was the incremental water from the upper reaches of the Tarim River. 225 The second was ecological water supply (Xue et al., 2019).

226 Seasonal variation characteristics of $\mathrm{CO}_{2}$ concentration (Fig. 3d) and RH (Fig. 3e) 227 were similar, with the highest values of 326ppmv and $79 \%$ in winter and the lowest 228 values of $271 \mathrm{ppmv}$ and $10 \%$ in summer. Photosynthesis was concentrated in summer, 229 so the $\mathrm{CO}_{2}$ concentration in the air was relatively low. Due to the high temperature in 230 summer, the air in the study site was dry, which was contrary to the conclusion that 231 RH was superior in the south of China. In general, the water resource in the arid 232 region is limited and the actual evapotranspiration is small (Zhu et al., 2018). 

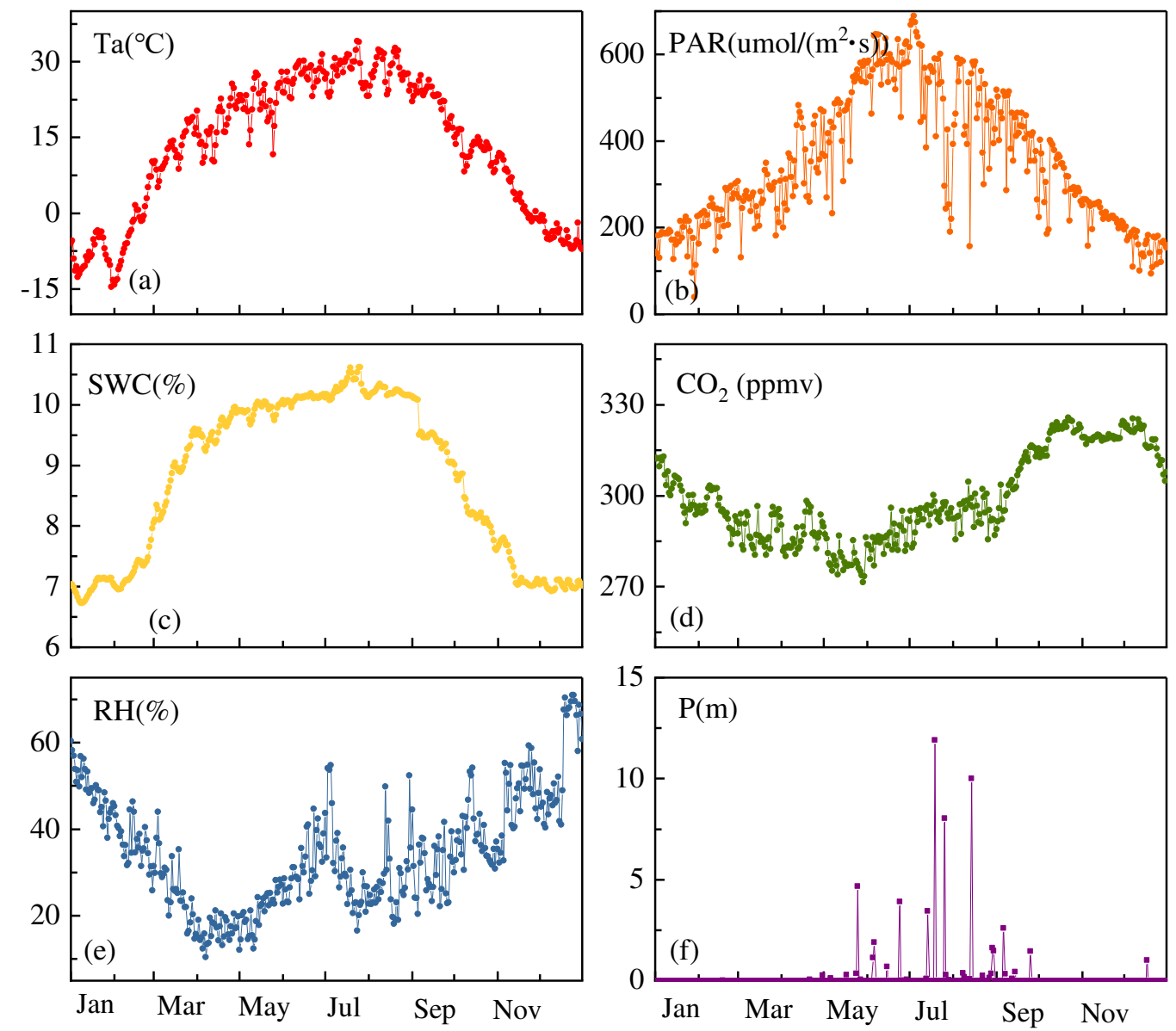

Month

234 Fig. 3. Seasonal variations in the daily mean environmental factors in 2018. (a) daily mean air temperature (Ta), (b)

235 daily mean photosynthetically active radiation (PAR), (c) daily mean soil water content (SWC) at $20 \mathrm{~cm}$, (d) daily

236 mean $\mathrm{CO}_{2}$ concentration, (e) daily mean air relative humidity $(\mathrm{RH})$, (f) daily precipitation (P).

\subsection{Evaluation results of EBR}

238 The turbulent energy $(\mathrm{LE}+\mathrm{H})$ observed by the EC system usually cannot balance

239 the available energy (RN-G). Wilson et al. (2002) analyzed the observation data from

24022 stations in the Global Flux Network, indicating that $10 \%-30 \%$ fluxes unclosed in

241 all stations. The energy fluxes obtained by the EC system were lower than that from

242 the radiometer. Some scholars (Stoy et al., 2013) have therefore started to suspect $\mathrm{CO}_{2}$

243 flux measurement result. The phenomenon of non-closing and its mechanism have 244 also become a hot spot in the study of turbulent flux.

245 The half-hourly fluxes had mean EBR of 0.74 in this study (Fig. 4a), within the 246 scope of international similar observations (0.55-0.99) (Wilson et al., 2002). Fig. 4b 247 was an ordinary linear regression of turbulent energy and available energy. The 
regression coefficient was 0.74, which was equal to the mean EBR. The EBR pattern

249 presented a general decrease from 9:30 to 20:00 in every season (Fig. 4c). During the 250 period of sufficient radiation (13:00-18:00), the EBR was very stable, close to 1.

251 However, compared with the available energy measured by the radiation system 252 and the soil heat flux measuring instrument, LE and $\mathrm{H}$ were underestimated. This was 253 primarily due to the weak turbulence at night. Moreover, the canopy heat storage term 254 was not considered, and the source region of the EC system was different from the 255 radiation observation system (Ding et al., 2010).
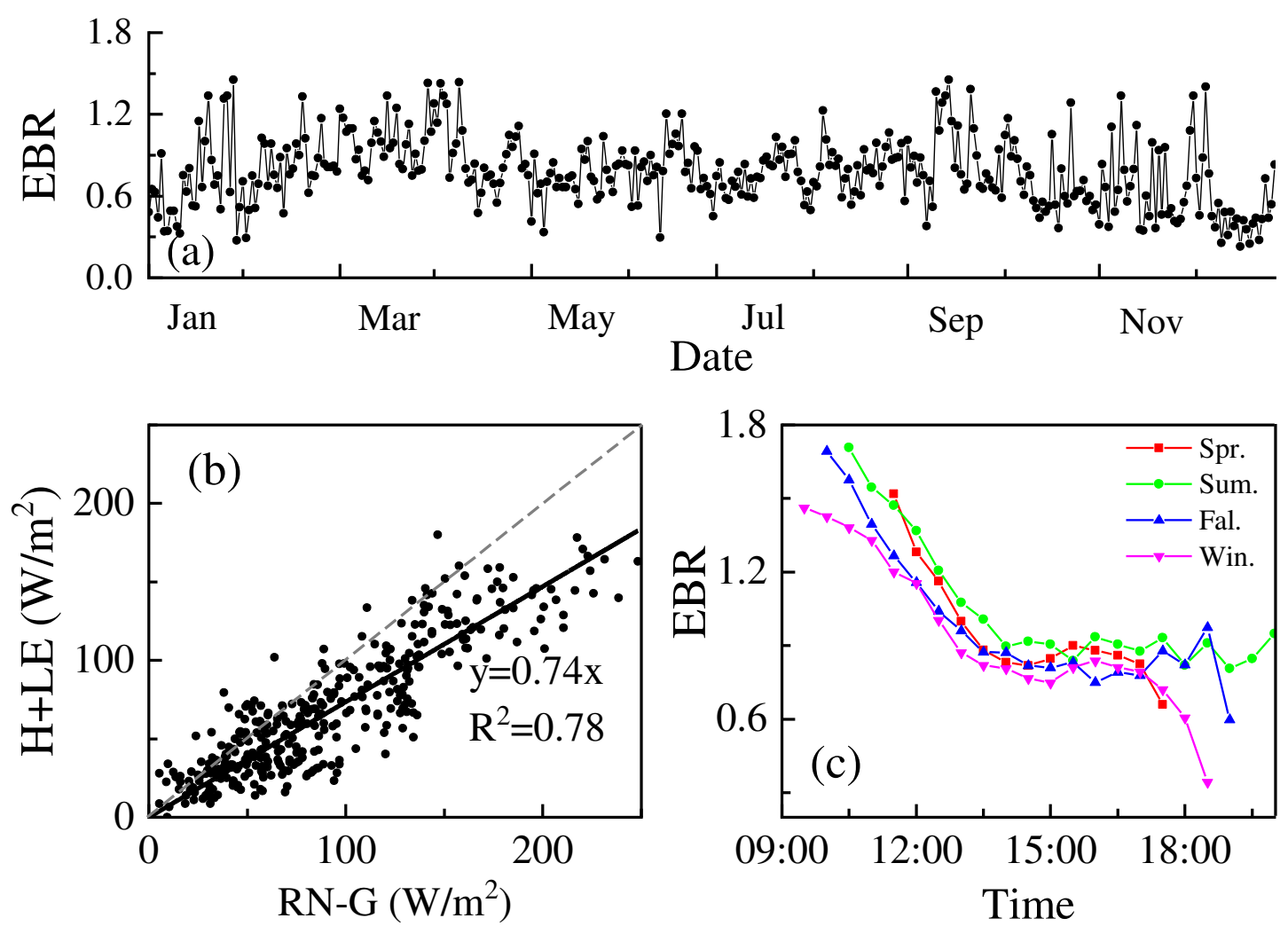

Fig. 4. (a) Daily mean EBR in 2018, (b) relationship between the turbulent flux (H+LE) and available energy (RN-G), (c) diurnal changes of EBR in different seasons. The EBR was not meaningful during the morning and evening transition periods when the mean value of $\mathrm{RN}-\mathrm{G}$ is close to zero.

\subsection{Seasonal and diurnal variations of energy fluxes}

261 Fig. 5a showed the monthly variation of energy fluxes. RN, as the outward driving 262 force of the soil-vegetation-atmosphere system, heats the atmospheric boundary layer 263 mainly in the form of $\mathrm{H}$ and LE, and some energy in the form of $\mathrm{G}$ enters soil 264 (Sánchez et al., 2009). The seasonal variation of LE, H and G was basically the same as 
RN. After October, the air temperature decreased with RN. However, due to the coverage of fallen leaves, the soil temperature did not decrease as rapidly as the air temperature. The soil temperature was higher than the air temperature, indicating that more heat stored in the soil, and the soil gradually released heat to the air. Since April, with the rapid increase of $\mathrm{RN}$, the heat stored in the soil became lower than that of air.

270 So, the atmosphere started to transmit heat to the soil. There were considerable 271 differences in seasonal variations of LE and $H$. LE was greater than $H$ in 272 June-September and lower than $\mathrm{H}$ in other months. LE varied between $10-113 \mathrm{~W} / \mathrm{m}^{2}$, 273 reaching its maximum in July and close to $10 \mathrm{~W} / \mathrm{m}^{2}$ in December, January and 274 February. LE characterizes the amount of surface ET, whose energy exchange is 275 linked to the phase transition of water. In summer, the temperature was high and the 276 ET was concentrated in the study area (Yan et al., 2006). There was a significant 277 seasonal variation in the ratio of every energy flux to $\mathrm{RN}$, indicating that the 278 proportion of energy consumed by vegetation life activities increased during the 279 growing season, while the proportion of energy consumed in the physical 280 environment decreased (Chan et al., 2018).

281 From the perspective of diurnal variation in energy fluxes (Figs. 4b-e), each energy 282 flux showed a unimodal curve and peaked around 14:00. The positive and negative 283 changes in energy fluxes were linked to the sunrise and sunset. From January to 284 March, RN was positive within one day for $10.5 \mathrm{~h}$, with an average of $255 \mathrm{~W} / \mathrm{m}^{2}$. From 285 April to June, RN was positive for $12.5 \mathrm{~h}$, with an average of $357 \mathrm{~W} / \mathrm{m}^{2}$. From July to 286 September, RN was positive for $10 \mathrm{~h}$, with an average of $184 \mathrm{~W} / \mathrm{m}^{2}$. From October to 287 December, RN was positive for $8 \mathrm{~h}$, with an average of $121 \mathrm{~W} / \mathrm{m}^{2}$. LE and $\mathrm{H}$ had 288 similar daily trends with RN. The peak time was basically the same as RN. $1 \mathrm{~h}$ after 289 sunrise, the soil-vegetation system began to assimilate energy. LE was on the brink of 290 zero from October to March. This explained by the fact that the ground was mostly 291 frozen, and the water vapor transmission was very weak during this time. The peak 292 value of LE in July was $215 \mathrm{~W} / \mathrm{m}^{2}$. From the perspective of $\mathrm{H}$, it reached a peak 
$293\left(254 \mathrm{~W} / \mathrm{m}^{2}\right)$ in April. The positive and negative changes in G were not only affected by 294 the sunrise time, but also by the soil. Owing to different soil physical and chemical 295 properties in different seasons, soil thermal conductivity was different. Therefore, the 296 delay time of soil heat absorption and heat dissipation was also altered. Negative 297 value of $\mathrm{G}$ indicated that heat radiated from the soil to the atmosphere and the soil 298 was the heat source. Conversely, the soil was heat sink (Sun et al., 2010).
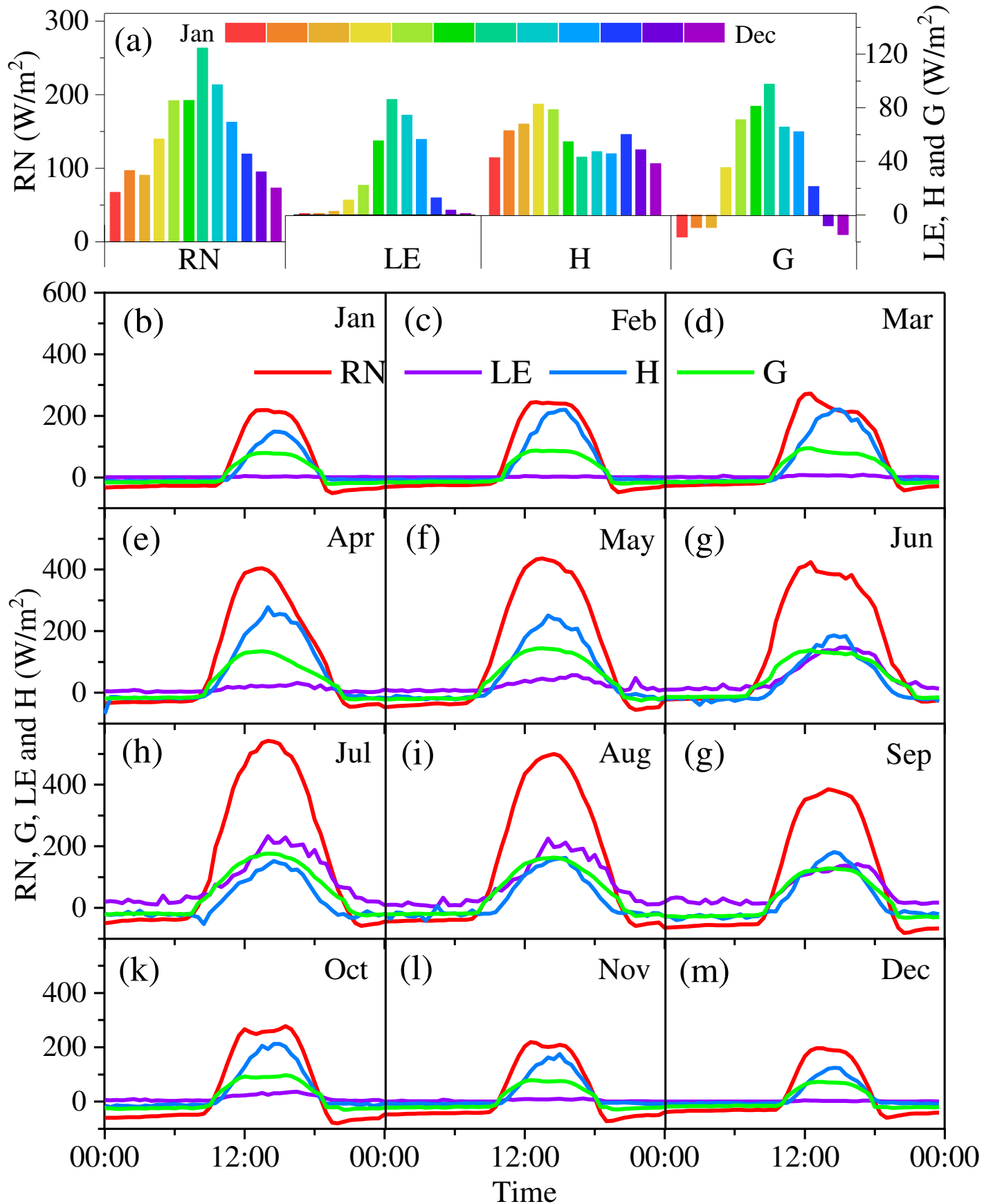

Fig. 5. Variations of net radiation (RN), soil heat flux (G), latent heat flux (LE), and sensible heat flux (H) in 2018.

301 (a) Monthly variations in energy fluxes, (b) -(m) diurnal variations in energy fluxes in different seasons. 
303 Carbon flux data was used to calculate the gross primary productivity (GPP), net 304 ecosystem productivity (NEP) and respiration (Re) of the Populus euphratica in 2018. 305 The seasonal variation characteristics were shown in Fig. 6a. GPP was generally 306 larger during the growing season (from April to October). During this period, the 307 photosynthesis and respiration of the ecosystem were relatively active. During the non-growth season from November to March of the following year, the temperature drop caused the vegetation to dry up, and the respiration of the entire ecosystem was

310 much greater than photosynthesis. GPP of the Populus euphratica ecosystem was $311877 \mathrm{~g} \mathrm{C} / \mathrm{m}^{2} / \mathrm{yr}$ and the maximum rate was $3.40 \mathrm{umol} /\left(\mathrm{m}^{2 *} \mathrm{~s}\right)$, which appeared in June. 312 The minimum production rate of GPP was $0.192 \mathrm{umol} /\left(\mathrm{m}^{2 *} \mathrm{~s}\right)$, which appeared in 313 December.

314 NEP was positive from May to September, indicating that photosynthesis in the 315 ecosystem was greater than respiration during this period, and the entire ecosystem 316 behaved as a carbon sink. NEP of the Populus euphratica ecosystem was $345 \mathrm{~g}$ $317 \mathrm{C} / \mathrm{m}^{2} / \mathrm{yr}$. The maximum production rate of $\mathrm{NEP}$ was $1.28 \mathrm{umol} /\left(\mathrm{m}^{2} * \mathrm{~s}\right)$, which appeared 318 in June. The minimum production rate of NEP was $-0.68 \mathrm{umol} /\left(\mathrm{m}^{2} * \mathrm{~s}\right)$, which appeared in March. The average production rate of NEP is $0.086 \mathrm{umol} /\left(\mathrm{m}^{2} *_{\mathrm{s}}\right)$.

320 The respiration intensity of Populus euphratica ecosystem was $532 \mathrm{~g} \mathrm{C} / \mathrm{m}^{2} / \mathrm{yr}$, 321 accounting for $61 \%$ of GPP. The respiration intensity of ecosystem was greater than 322 NEP. The seasonal change of respiration showed a single peak curve, which increased 323 from February to August. The maximum rate of respiration rate was $2.51 \mathrm{umol} /\left(\mathrm{m}^{2 *} \mathrm{~s}\right)$, 324 which occurred in August, and the minimum value was $0.04 \mathrm{umol} /\left(\mathrm{m}^{2} *_{\mathrm{s}}\right)$, which 325 occurred in February. The average respiration rate of Populus euphratica ecosystem 326 was $0.97 \mathrm{umol} /\left(\mathrm{m}^{2} *_{\mathrm{s}}\right)$.

327 The diurnal variation characteristics of GPP, NEP and Re were shown in Figs. $3286 \mathrm{~b}-\mathrm{m}$. Similar to the diurnal variation of energy flux (Figs. 5b-m), their variations 329 also showed a single-peak curve. During January-March, April-June, July-September 
and October-December, GPP and NEP from 12:00 to 19:00, 9:30 to 20:30, 10:30 to

$33121: 00$ and 10: 30 to 18:30 was a positive value. It indicated that the ecosystems

332 absorbed carbon and the duration was 7, 11, 10.5 and 8.5h, respectively. However, the

333 peak time (15:00) was about an hour later than the energy flux (14:00).
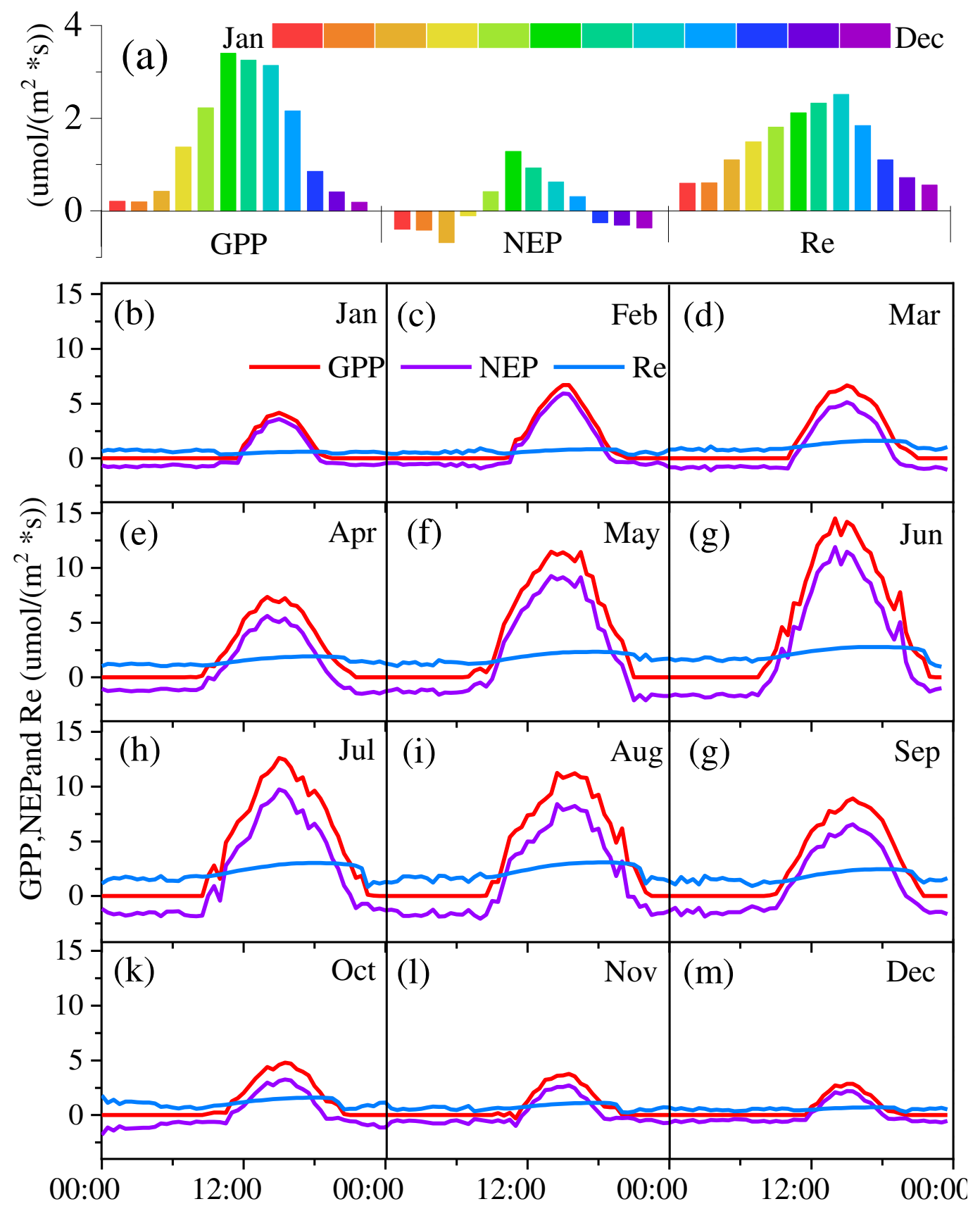

Time

Figure 6. Variations of gross primary productivity (GPP), net ecosystem productivity (NEP), and total respiration

(Re) in 2018. (a) Monthly variations, (b) -(m) diurnal variations.

\subsection{Seasonal and diurnal variations of WUE}

338 In the Populus euphratica ecosystem, ET was close to zero in winter (Fig. 7), so 
only the WUE of the growing seasons was calculated. During this period, the mean

340 WUE was $2.2 \mathrm{~g} \mathrm{C} / \mathrm{kg} \mathrm{H}_{2} \mathrm{O}$ and the maximum WUE was $5.5 \mathrm{~g} \mathrm{C} / \mathrm{kg} \mathrm{H}_{2} \mathrm{O}$. Due to the 341 combined effects of photosynthesis and evapotranspiration, WUE didn't peak when 342 GPP and ET reached their highest values. WUE was opposite to the trend of 343 photosynthetic and evapotranspiration. This showed that WUE of the Populus 344 euphratica ecosystem was not necessarily high when GPP and ET were high. Under 345 the conditions of high temperature, strong radiation and low humidity in summer, the 346 growth rate of ET was much larger than that of GPP.

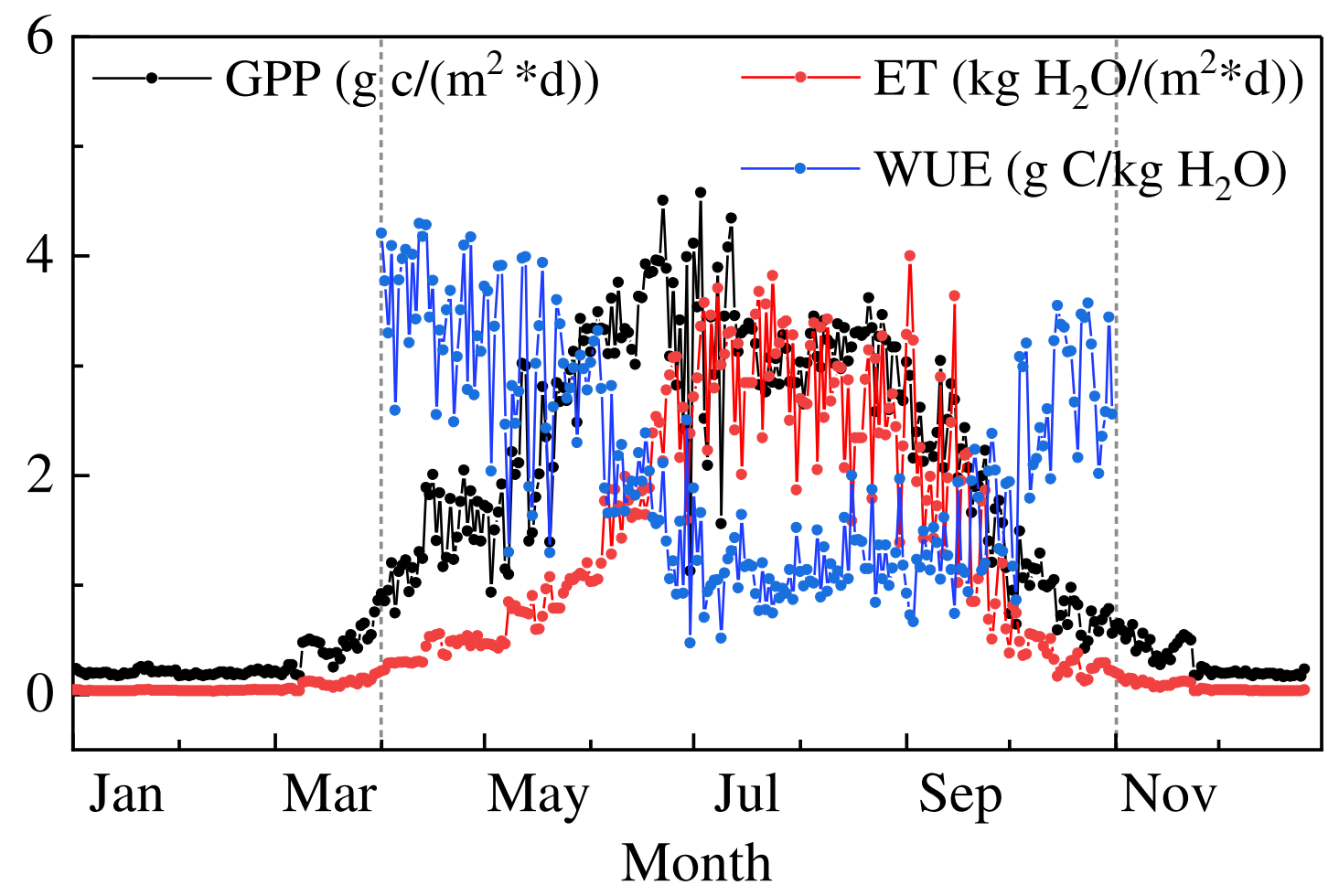

Figure 7. Daily gross primary productivity (GPP), evapotranspiration (ET) and water use efficiency (WUE)

349 during the growing seasons (April-October) in 2018.

350 The instantaneous WUE in daytime (8:30-20:00) was calculated using fluxes data 351 at a frequency of $30 \mathrm{~min}$ (Fig. 8). We eliminated the data from 20:30 to 8:00 because 352 WUE in night was of little significance, and the change rate of WUE was larger when 353 the illumination was low. The daily variation of WUE in each month of the growing 354 season was basically the same. WUE gradually increased with the enhancement of radiation (Fig. 5), reached a maximum at 14:00, and then gradually decreased. 


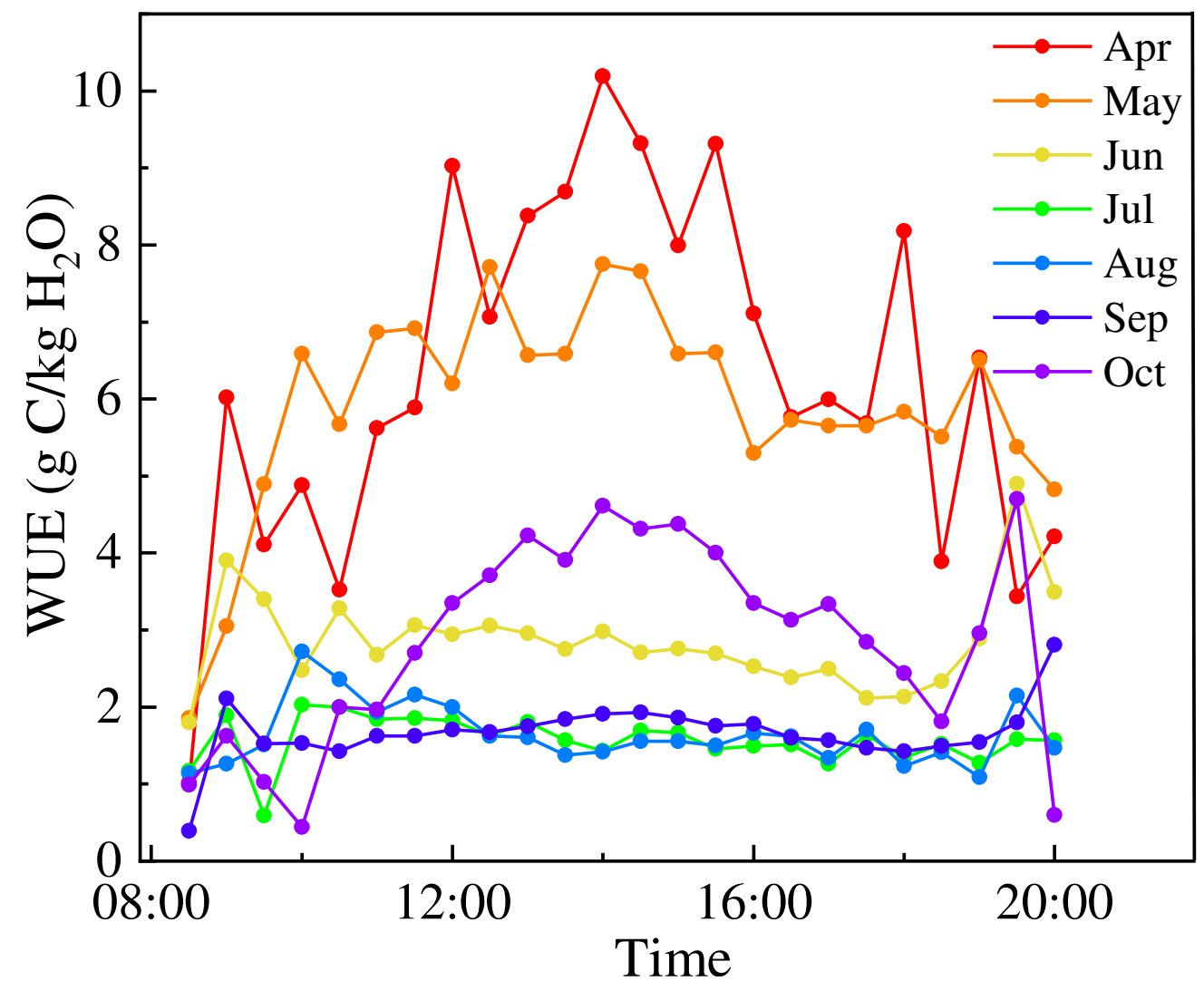

Figure 8. Diurnal water use efficiency (WUE) during the growing seasons (April-October) in 2018.

\subsection{Effects of climatic variables on WUE}

Various environmental factors influenced WUE by controlling vegetation photosynthetic and transpiration (Kuglitsch et al., 2008). Both photosynthesis and evapotranspiration will increase with temperature. However, the growth rate is different, and the value of the ecosystem WUE determined by the two is also different (Wolf et al., 2013; Wu et al., 2017). In Populus euphratica forest, WUE became smaller as Ta increased (Fig. 9a). This is because ET increased greater than photosynthesis with increasing temperature.

It can be seen from Fig. 9b that WUE decreased as PAR increased. Solar radiation first affects the stomatal conductance of vegetation leaves, and then photosynthesis and transpiration change accordingly. Although PAR is the source of photosynthesis, the impact on transpiration is different. Plant photosynthesis only takes place within a certain range of radiation. Photosynthesis is limited with the increase of PAR, and there will be light saturation phenomenon. However, there is no upper limit for

372 transpiration. Under sufficient water conditions, light will cause the temperature to 
rise, and transpiration will continue to strengthen.

The water for vegetation growth in Populus euphratica forest ecosystem mainly comes from soil water. Therefore, soil water is an important factor influencing WUE. Fig. 9c showed that WUE increased as SWC decreased. The study area is in an arid area, so the vegetation often closes the leaf stomata due to lacking water. As a result, evapotranspiration decreased, and WUE increased accordingly. Moderate drought is beneficial to improve WUE (Krishnan et al., 2006; Yang et al., 2016), but if the drought continues to increase, the intensity of photosynthesis will decrease (Zhao et al., 2007). It is another matter to reduce or continue to maintain WUE under this result.

The increase of $\mathrm{CO}_{2}$ concentration promoted the increase of WUE (Fig. 9d). There are two reasons. For one thing, increased $\mathrm{CO}_{2}$ concentration will directly promote vegetation photosynthesis. For another, increased $\mathrm{CO}_{2}$ concentration will cause the vegetation leaf stomata to close, and the water consumption will decrease. Thus vegetation can convert more water into productivity (Forner et al., 2018).

RH was the main environmental factor affecting WUE (Figure 9e). Most studies have found a linear positive correlation between RH and WUE, but some studies have reached the opposite conclusion ( $\mathrm{Li}$ et al., 2008). The reasons for the two diametrically opposite research results may be related to the soil water content.

Fig. 9f showed that WUE decreased sharply with the increase of P and then slowly decreased. Although the increase in precipitation could improve the GPP of the ecosystem, ET increased faster. 

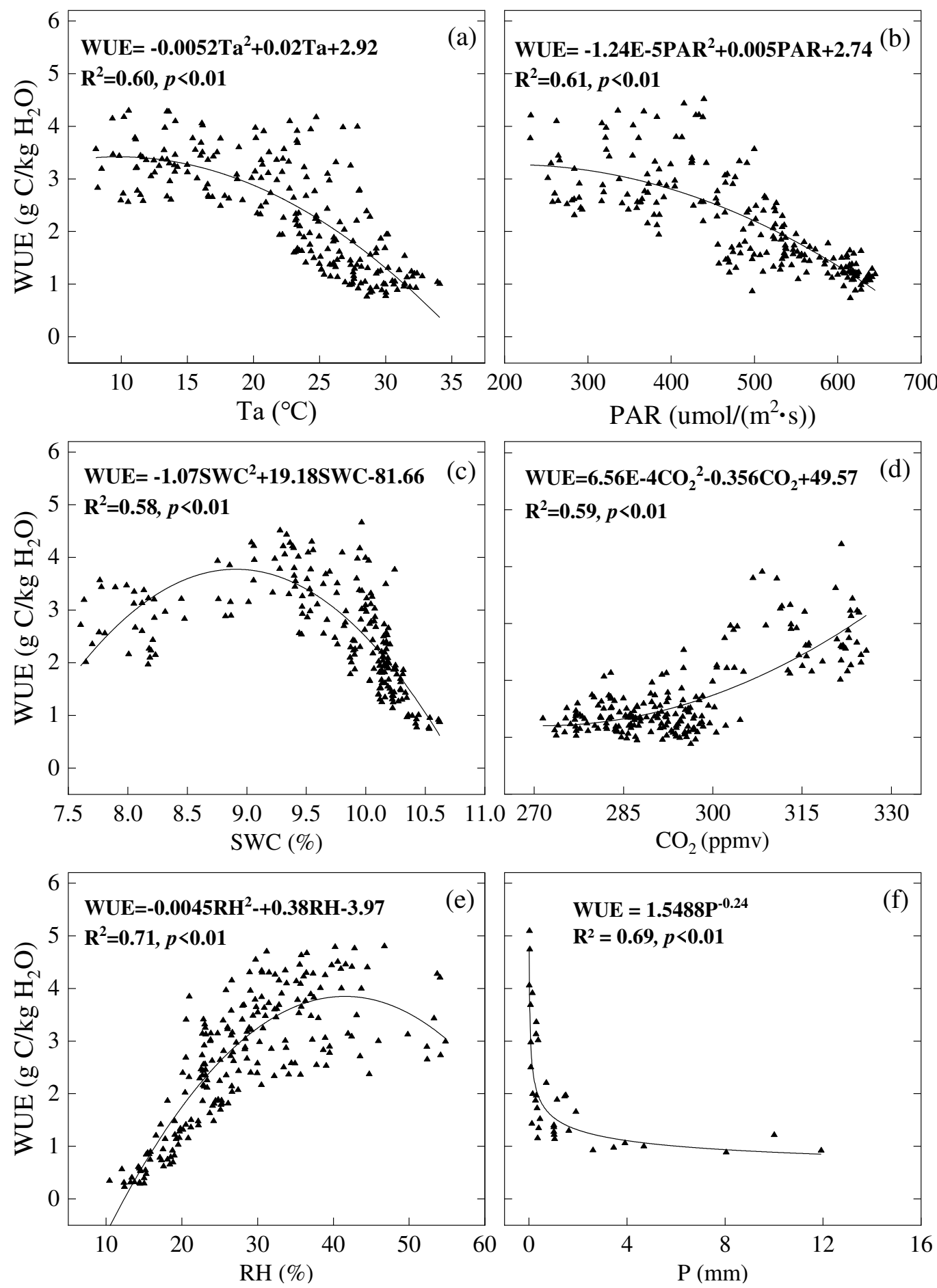

Figure 9. Relationship between water use efficiency (WUE) and (a) air temperature (Ta), (b) photosynthetically active radiation (PAR), (c) soil water content (SWC), (d) carbon dioxide concentration $\left(\mathrm{CO}_{2}\right)$, (e) air relative humidity (RH), (f) precipitation (P) during the growing seasons (April-October).

\subsection{Evapotranspiration characteristics at different time scales}

400 The main form of LE is water phase change, so the variation of ET is similar to the

401 LE (Fig. 5a). The annual ET of the Populus euphratica ecosystem was about 345mm. 
402 The evapotranspiration process mainly occurred from May to October at 286mm, 403 accounting for $93 \%$ of the annual evapotranspiration, indicating that the ET in this 404 area was relatively concentrated. Vegetation of the Populus euphratica ecosystem has 405 grown rapidly since April. As the temperature rises, the melting snow at the source of 406 the Tarim River supplements the amount of water in the channel. In addition, summer 407 rainfall is relatively high. River water and groundwater are abundant. These 408 conditions are conducive to the growth of vegetation while also accelerating the 409 evaporation and transpiration of the ecosystem.

410 The daily evapotranspiration of the Populus euphratica ecosystem was basically 411 close to zero from November to March (Figs. 10b-m). At the same time as the 412 temperature decreased, it became difficult for vegetation to grow, and the water 413 consumption of the ecosystem also decreased sharply. The maximum value of daily 414 evapotranspiration occurred in July at $3.82 \mathrm{~mm}$. The daily changes of 415 evapotranspiration in July and August were basically similar, and both reached their 416 maximum around 14:30 pm. Evapotranspiration lasts from 11:30 to 19:30 at a high 417 value. 


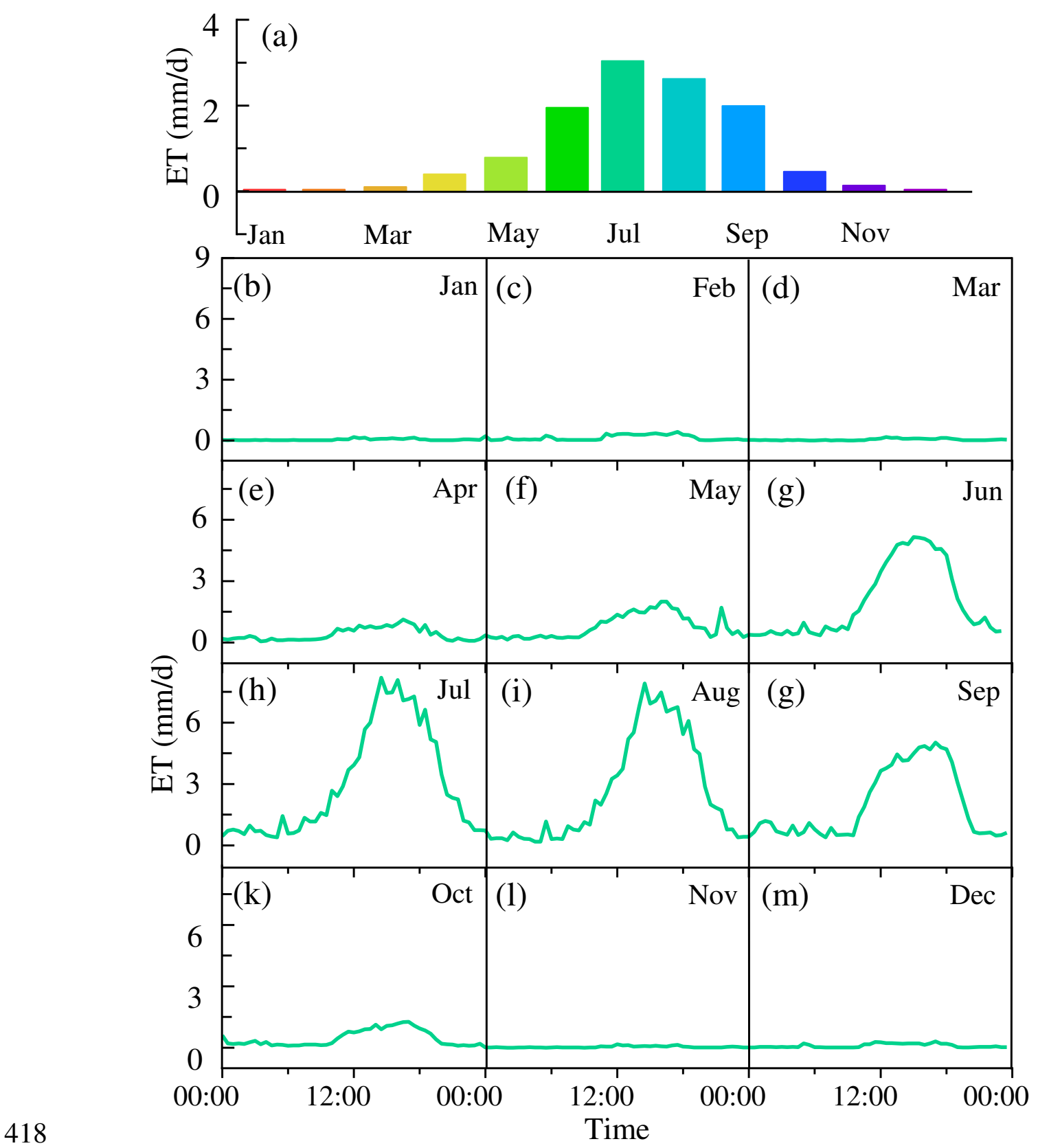

419 Figure 10. Variations of evapotranspiration (ET) in 2018. (a) Monthly variations, (b) -(m) diurnal variations.

\section{Discussion}

\subsection{Comparison of WUE with other ecosystems}

422 The daily average WUE $\left(2.2 \mathrm{~g} \mathrm{C} \mathrm{kg} \mathrm{H}_{2} \mathrm{O}\right)$ of the Populus euphratica ecosystem was

423 lower than other temperate forest ecosystems (2.57-6.07g $\mathrm{C} / \mathrm{kg} \mathrm{H}_{2} \mathrm{O}$ ) (Tan et al., 424 2015). When compared with forests of the same latitude, WUE of Populus euphratica 425 forest was not as high as other forests in non-arid regions, but higher than grassland, 426 wetland and crop land (Fig. 11), because long-term drought enhanced the ecosystem's 
resistance and resilience to water scarcity in order to mitigate the effects of water loss (Gang et al., 2016).

In addition, we found that the WUE of Populus euphratica was relatively low, which was closely related to the local climatic conditions. During the growing season, although the ecosystem had the highest GPP, intense ET led to more water consumption while absorbing the same amount of carbon.

\subsection{Latitudinal trends of WUE in different vegetation types}

It is widely known that the vegetation types, stand structure, soil type, stand age, and geological evolution of terrestrial ecosystems vary widely. WUE had a clear zonal change trend (Fig. 10). As the latitude increased from tropical to high latitudes in the north, the average WUE of different ecosystems for many years has shown an upward trend, peaking at about $51^{\circ} \mathrm{N}$, and then tending to decline at high latitudes. Although the WUE of different plant type ecosystems was different, all the peaks occurred within approximately the same latitude range $\left(45^{\circ} \mathrm{N}-55^{\circ} \mathrm{N}\right)$. This indicated that there was a key zone of differentiation driven by radiation and moisture. In fact, latitude itself is not a driving variable, but a complex proxy factor under the combined action of abiotic and biological factors, which determines the main ecological zone (Tang et al., 2014).

However, in the case of the same latitude range, there were also differences in the size of WUE among different vegetation groups (Fig. 10). The WUE of evergreen forests was higher than that of deciduous vegetation at the same latitude. Broad-leaved forests had higher WUE than coniferous forests. The overall WUE of the forest ecosystem was higher than that of grasslands, wetlands and crop land. Except for the wetland ecosystem, WUE of crop land was the lowest, which might be affected by the unproductive stage, and the soil evaporation was higher than that of permanent vegetation. 


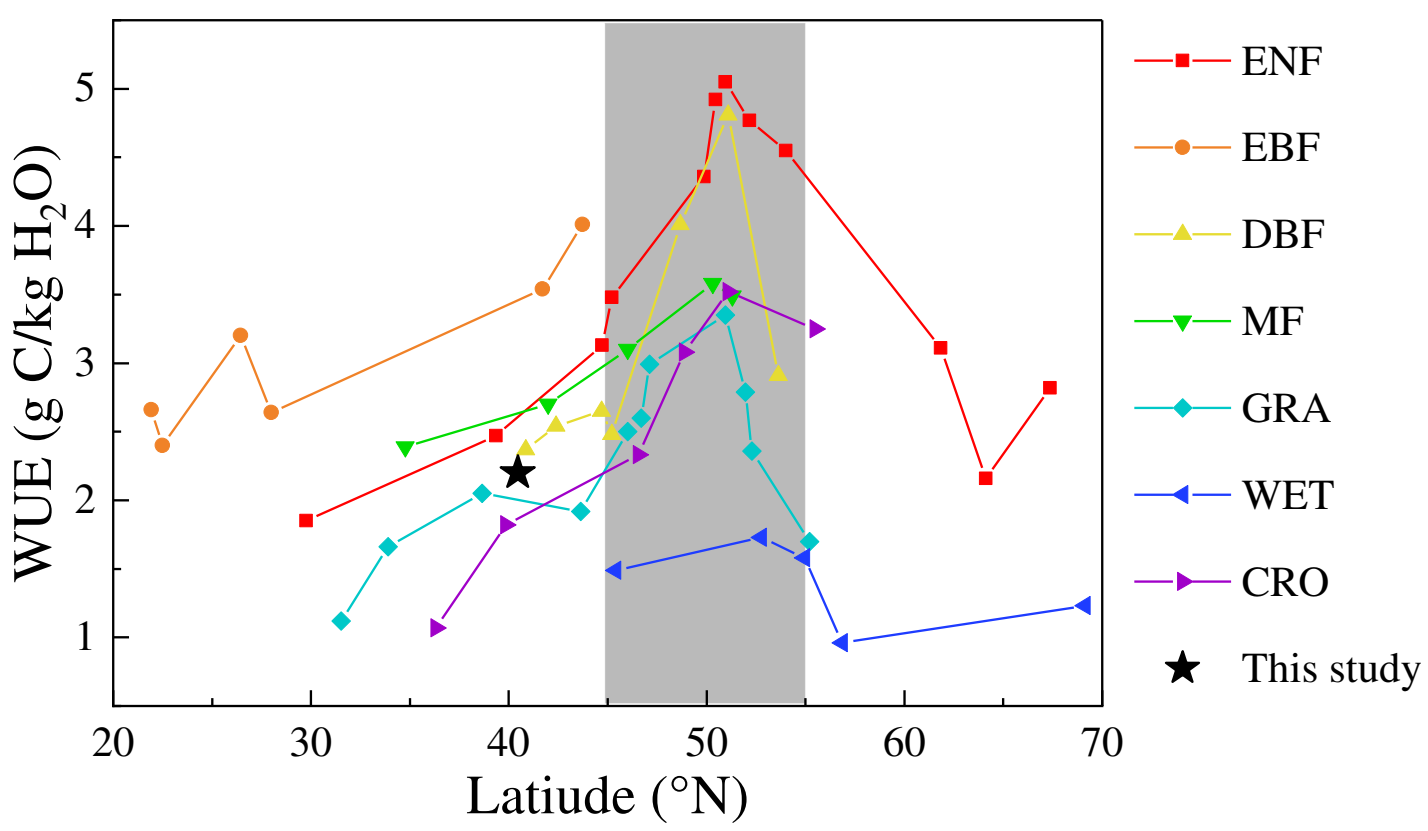

453

454

455

Figure 11. Latitudinal trends in multiyear mean annual WUE for different plant functional types. ENF, EBF, DBF,

MF, GRA, WET and CRO represent evergreen needleleaf forest, evergreen broadleaved forest, deciduous broadleaved forest, mixed forest, grassland, wetland and cropland, respectively. References: Beer et al. [2009], Tang et al. [2014], Tan et al. [2014], Kwon et al. [2018], Quansah et al. [2015], Gang et al. [2016], Chatterjee et al. [2018], Zanotelli et al. [2013].

\section{Conclusions}

Patterns in ecosystem carbon, water, energy fluxes and WUE of Populus euphratica forest in northwest China were studied in light of combined influences of environmental variables and plant biological processes. The main conclusions are as follows:

(1) The energy fluxes of the Populus euphratica ecosystem were not closed. The average EBR was 0.74, which was within the range of international comparable observations $(0.55-0.99)$.

(2) Seasonal variations of RN, G, LE and H all showed a unimodal curve. With the exception of $\mathrm{H}$, each energy flux reached its maximum in summer. From the perspective of the diurnal variations, each energy flux also showed a unimodal curve based on RN, reaching a peak around 14:00.

(3) The carbon exchange in the Populus euphratica ecosystem mainly occurred 
472 from April to October, and the whole ecosystem showed a strong carbon sink. From

473 December to February, the ecosystem became a carbon source. Annual GPP, NPP and

$474 \mathrm{Re}$ were $877,345,532 \mathrm{~g} \mathrm{C} / \mathrm{m}^{2}$, respectively. The daily maximum ET appeared in July

$475(3.82 \mathrm{~mm})$ and the annual evaporation was about $345 \mathrm{~mm}$.

476 (4) During the growing seasons, the mean and maximum daily WUE was 2.2 and $4775.5 \mathrm{~g} \mathrm{C} / \mathrm{kg} \mathrm{H} \mathrm{H}_{2} \mathrm{O}$. WUE decreased with increasing Ta, PAR, and NDVI. $\mathrm{CCO}_{2}$ and $\mathrm{RH}$ 478 could promote the growth of WUE. WUE increased under moderate SWC condition. 479 Under the conditions of high temperature, strong radiation and low humidity in 480 summer, the growth rate of ET was much larger than that of GPP, causing WUE to 481 drop to the lowest point.

482 (5) WUE of the Populus euphratica ecosystem was lower than other temperate 483 forest ecosystems, but higher than grassland, wetland and crop land. By comparing 484 WUE of various types of terrestrial ecosystems, we found that WUE exhibited 485 significant spatial variability with geographical location and climate, but the peaks of 486 different plant functional types occurred within approximately the same latitude range $487 \quad\left(45^{\circ} \mathrm{N}-55^{\circ} \mathrm{N}\right)$.

\section{Conflict of Interest}

489 The authors declare that they have no known competing financial interests or 490 personal relationships that could have appeared to influence the work reported in this 491 paper.

492 Funding Statement

493 This study was supported by the National Natural Scientific Foundation of China 494 (NSFC) (No.51779074, No.41371052) and the State's Key Project of Research and 495 Development Plan (2017YFC0404304).

496 Author's Contribution

497 Fangbing Fu: Writing - original draft, Methodology, Software, Data curation. 
Lianqing Xue: Methodology, Supervision, Writing - review \& editing, Project

499 administration, Funding acquisition. Xinfang Chen: Supervision, Review. Yuanhong

500 Liu: Software, Data curation. Qiang Han: Resources. Shumin Liao: Writing,

501 Software. Qing Wei: Investigation.

502 Availability of data and material

503 All data generated or analysed during this study are included in this article.

504 Code availability

$505 \quad$ Not applicable.

506 Ethics approval

$507 \quad$ Not applicable.

508 Consent to participate

509 All the authors read and approved the final version of the manuscript. The authors 510 agree to publish the article.

511 Consent for publication

512 The authors confirm that the work described has not been published before, and it 513 is not under consideration for publication elsewhere.

514 References

515 Amiro, B.D., Barr, A.G., Black, T.A., Iwashita, H., Kljun, N., McCaughey, J.H., 516 Morgenstern, K., Murayama, S., Nesic, Z., Orchansky, A.L., Saigusa, N., 2006. 517 Carbon, energy and water fluxes at mature and disturbed forest sites, 518 Saskatchewan, Canada. Agricultural and Forest Meteorology, 136, 237-251.

519 Beer, C., Ciais, P., Reichstein, M., Baldocchi, D., Law, B.E., Papale, D., Soussana, 520 J.F., Ammann, C., Buchmann, N., Frank, D., Gianelle, D., Janssens, I.A., Knohl, 521 A., Kostner, B., Moors, E., Roupsard, O., Verbeeck, H., Vesala, T., Williams, C.A., 
Wohlfahrt, G., 2009. Temporal and among-site variability of inherent water use efficiency at the ecosystem level. Global Biogeochemical Cycles, 23, GB2018.

Brümmer, C., Black, T.A., Jassal, R.S., Grant, N.J., Spittlehouse, D.L., Chen, B., Nesic, Z., Amiro, B.D., Arain, A.F., 2012. How climate and vegetation type influence evapotranspiration and water use efficiency in Canadian forest, peatland and grassland ecosystems. Agricultural and Forest Meteorology, 153, 14-30.

Chan, F.C.C., Arain, M.A., Khomik, M., Brodeur, J.J., Peichl, M., Restrepo-Coupe, N., Thorne, R., Beamesderfer, E., McKenzie, S., Xu, B., Croft, H., Pejam, M., Trant, J., Kula, M., Skubel, R., 2018. Carbon, water and energy exchange dynamics of a young pine plantation forest during the initial fourteen years of growth. Forest Ecology and Management, 410, 12-26.

Chatterjee, D., Tripathi, R., Chatterjee, S., Debnath, M., Shahid, M., Bhattacharyya, P., Swain, C.K., Tripathy, R., Bhattacharya, B.K., Nayak, A.K., 2018. Characterization of land surface energy fluxes in a tropical lowland rice paddy. Theoretical and Applied Climatology, 136, 157-168.

Sánchez, J.M., Caselles, V., Niclòs, R., Coll, C., Kustas, W.P., 2009. Estimating energy balance fluxes above a boreal forest from radiometric temperature observations. Agricultural and Forest Meteorology, 149, 1037-1049.

Ding, R.S., Kang, S.Z., Li, F.S., Zhang, Y.Q., Tong, L., Sun, Q.Y., 2010. Evaluating eddy covariance method by large-scale weighing lysimeter in a maize field of northwest China. Agricultural Water Management, 98(1), 87-95.

Fei, D.Y., Guo, J.M., Liu, J.W., W, Q., 2018. Light use efficiency estimation of rice

546 Foken, T., Göckede, M., Mauder, M., Mahrt, L., Amiro, B.D., Munger, J.W., 2004.

547 Postfield data quality control. In: Lee, X., Massman, W.J., Law, B. (Eds.), 548 Handbook of Micrometeorology: A Guide for Surface Flux Measurement and 549 Analysis. Kluwer, Dordrecht, pp. 181-208. 
Forner, A., Valladares, F., Bonal, D., Granier, A., Grossiord, C., Aranda, I., 2018. Extreme droughts affecting Mediterranean tree species' growth and water-use

553 efficiency: the importance of timing. Tree Physiology, 38 (8), 1127-1137.

Gang, C.C., Wang, Z.Q., Chen, Y.Z., Yang, Y., Li, J.L., Cheng, J.M., Qi, J.G., Odeh, I., 2016. Drought-induced dynamics of carbon and water use efficiency of global grasslands from 2000 to 2011. Ecological Indicators, 67, 788-797.

Govind, A., Chen, J.M., Mcdonnell, J., Kumari, J., Sonnentag, O., 2011. Effects of lateral hydrological processes on photosynthesis and evapotranspiration in a boreal ecosystem. Ecohydrology, 4(3), 394-410.

Hui, D.F., Luo, Y.Q., Cheng, W.X., Coleman, J.S., Johnson, D.W., Sims, D.A., 2001. Canopy radiation- and water-use efficiencies as affected by elevated [CO2]. Global Change Biology, 7, 75-91.

Jassal, R.S., Black, T.A., Spittlehouse, D.L., Brümmer, C., Nesic, Z., 2009. Evapotranspiration and water use efficiency in different-aged Pacific Northwest Douglas-fir stands. Agricultural and Forest Meteorology, 149, 1168-1178.

Jin, J.X., Zhan, W.F., Wang, Y., Gu, B.J., Wang, W.F., Jiang, H., Lu, X.H., Zhang, X.Y., 2017. Water use efficiency in response to interannual variations in flux-based photosynthetic onset in temperate deciduous broadleaf forests. Ecological Indicators, 79, 122-127.

Kim, J., Hirano, T., Yu, G.R., Li, S.G., Tamai, K., 2013. Lessons learned from CarboEastAsia: carbon and water cycles in East Asian terrestrial ecosystems. Journal of Forest Research, 18, 1-3.

Kominami, Y., Jomura, M., Dannoura, M., Goto, Y., Tamai, K., Miyama, T., Miyama, T., Kanazawa, Y., Kaneko, S., Okumura, M., Misawa, N., Hamada, S., Sasaki, T., Kimura, H., Ohtani, Y., 2008. Biometric and eddy-covariance-based estimates of carbon balance for a warm-temperate mixed forest in Japan. Agricultural and Forest Meteorology, 148(5), 723-737.

Krishnan, P., Black, T.A., Grant, N.J., Barr, A.G., Hogg, E.H., Jassal, R.S., 
Morgenstern, K., 2006. Impact of changing soil moisture distribution on net ecosystem productivity of a boreal aspen forest during and following drought. Agricultural and Forest Meteorology, 139, 208-223.

581 Kuglitsch, F.G., Reichstein, M., Beer, C., Carrara, A., Ceulemans, R., Granier, A., 582 Janssens, I.A., Koestner, B., Lindroth, A., Loustau, D., Matteucci, G., Montagnani, 583 L., Moors, E.J., Papale, D., Pilegaard, K., Rambal, S., Rebmann, C., Schulze, E.D., 584 Seufert, G., Verbeeck, H., Vesala, T., Aubinet, M., Bernhofer, C., Foken, T., 585 Grünwald, T., Heinesch, B., Kutsch, W., Laurila, T., Longdoz, B., Miglietta, F., 586 Sanz, M.J., Valentini, R., 2008. Characterisation of ecosystem water-use 587 efficiency of European forests from eddy covariance measurement. $588 \quad$ Biogeosciences Discuss, 5, 4481-4519.

589 Kwon, H., Creason, W., Law, B.E., Still, C.J., Hanson, C., 2018. Influence of 590 concurrence of extreme drought and heat events on carbon and energy fluxes in 591 dominant ecosystems in the Pacific Northwest region, Biogeosciences Discuss, $592 \quad 297,1-31$.

593 Li, S., Eugster, W., Asanuma, J., Kotani, A., Davaa, G., Oyunbaatar, D., Sugita, M., 594 2008. Response of gross ecosystem productivity, light use efficiency, and water 595 use efficiency of Mongolian steppe to seasonal variations in soil moisture. Journal 596 of Geophysical Research, 113, G01019.

597 Linderson, M.L., Mikkelsen, T.N., Ibrom, A., Lindroth, A., Ro-Poulsen, H., Pilegaard, 598 K., 2012. Up-scaling of water use efficiency from leaf to canopy as based on leaf 599 gas exchange relationships and the modelled in-canopy light distribution. $600 \quad$ Agricultural and Forest Meteorology, 152, 201-211.

601 Keenan, T.F., Hollinger, D.Y., Bohrer, G., Dragoni, D., Munger, J.W., Schmid, H.P., 602 Richardson, A.D., 2013. Increase in forest water-use efficiency as atmospheric 603 carbon dioxide concentrations rise. Nature, 499, 324-327.

604 Ma, J.Y., Jia, X., Zha, T.S., Bourque, C.P.-A., Tian, Y., Bai, Y.J., Liu, P., Yang, R.Z., Li, 605 C., Li, C.Y., Xie, J., Yu, H.Q., Zhang, F., Zhou, C.X., 2019. Ecosystem water use 

efficiency in a young plantation in Northern China and its relationship to drought. Agricultural and Forest Meteorology, 275, 1-10.

Chen, Y.N., Li, W.H., Zhou, H.H., Chen, Y.P., Hao, X.M., Fu, A.H., Ma, J.X., 2017. Experimental study on water transport observations of desert riparian forests in the lower reaches of the Tarim River in China. Int. J. Biometeorol., 61,

612 Mammarella, I., Nordbo, A., Rannik, U., Haapanala, S., Levula, J., Laakso, H., Ojala, A., Peltola, O., Heiskanen, J., Pumpanen, J., Vesala, T., 2015. Carbon dioxide and energy fluxes over a small boreal lake in Southern Finland. Journal of Geophysical Research: Biogeosciences, 120(7), 1296-1314.

Meyers, T.P., Hollinger, S.E. 2004. An assessment of storage terms in the surface

Ponton, S., Flanagan, L.B., Alstad, K.P., Johnson, B.G., Morgenstern, K., Kljun, N., Black, T.A., Barr, A.G., 2006. Comparison of ecosystem water-use efficiency among douglas fir forest, aspen forest and grassland using eddy covariance and carbon isotope techniques. Global Change Biology, 12, 294-310.

Quansah, E., Mauder, M., Balogun, A.A., Amekudzi, L.K., Hingerl, L., Bliefernicht,

630 Seddon, A.W.R., Macias-Fauria, M., Long, P.R., Benz, D., Willis, K.J., 2016.

631 Sensitivity of global terrestrial ecosystems to climate variability. Nature, 531, 632 229-232. 
Kula, M., 2015. Age effects on the water-use efficiency and water-use dynamics of temperate pine plantation forests. Hydrological Processes, 29, 4100-4113.

Stephens, J.J., Black, T.A., Jassal, R.S., Nesic, Z., Grant, N.J., Barr, A.G. , Helgason, W.D., Richardson A.D., Johnson M.A., Christen A., 2018. Effects of forest tent caterpillar defoliation on carbon and water fluxes in a boreal aspen stand. Agricultural and Forest Meteorology, 253-254, 176-189.

Stoy, P.C., Mauder, M., Foken, T., Marcolla, B., Boegh, E., Ibrom, A., Arain, M.A., Arneth, A., Aurela, M., Bernhofer, C., Cescatti, A., Dellwik, E., Duce, P., Gianelle,

Tan, Z.H., Zhang, Y.P., Deng, X.B., Song, Q.H., Liu, W.J., Deng, Y., Tang, J.W., Liao, Z.Y., Zhao, J.F., Song, L., Yang, L.Y., 2015. Interannual and seasonal variability of water use efficiency in a tropical rainforest: results from a 9 year eddy flux time series. Journal of Geophysical Research: Atmospheres, 120, 464-479.

Tang, X.G., Li, H.P., Desai, A.R., Nagy, Z., Luo, J.H., Kolb, T.E., Olioso, A., Xu, X.B., water-use efficiency of terrestrial ecosystems distributed and changing on earth? Scientific Reports, 4, 7483.

Tong, X.J, Zhang, J.S, Meng, P., Li, J., Zheng, N., 2014. Ecosystem water use 659 efficiency in a warm-temperate mixed plantation in the North China. Journal of Hydrology, 512, 221-228.

Wang, W.J., Cui, S., Liu, W., Zu, Y.G., Sun, W., Wang, H.M., 2008. Seasonal variation

661 Wang, Y.J., Guo, Y.H., 2018. Characteristics of Oasis before and after the ecology 

water transportation in lower reaches of the Tarim River. Desert and Oasis Meteorology, 68(2), 41-46.

Wilson, K., Goldstein, A., Falge, E., Aubinet, M., Baldocchi, D., Berbigier, P., 665 Bernhofer, C., Ceulemans, R., Dolman, H., Field, C., Grelle, A., Ibrom, A., Law, B.E., Kowalski, A., Meyers, T., Moncrieff, J., Monson, R., Oechel, W., Tenhunen, J., Valentini, R., Verma, S., 2002. Energy balance closure at FLUXNET sites. Agricultural and Forest Meteorology, 113, 223-243.

Wolf, S., Eugster, W., Ammann, C., Häni, M., Zielis, S., Hiller, R., Stieger, J., Imer, D., Merbold, L., Buchmann, N., 2013. Contrasting response of grassland versus forest carbon and water fluxes to spring drought in Switzerland. Environmental Research Letters, 8 (3), 035007.

Wu, X., Liu, H., Li, X., Ciais, P., Babst, F., Guo, W., Zhang, C., Magliulo, V., Pavelka, 677 M., Liu, S., Huang, Y., Wang, P., Shi, C., Ma, Y., 2017. Differentiating drought legacy effects on vegetation growth over the temperate northern hemisphere. Global Change Biology, 24 (1), 504-516.

Xu, L.K., Hsiao, T.C., 2004. Predicted versus measured photosynthetic water-use efficiency of crop stands under dynamically changing field environments. Journal of Experimental Botany, 55(407), 2395-2411.

Xue, L.Q., Wang, J., Zhang, L.C., Wei, G.H., Zhu, B.L., 2019. Spatiotemporal 682 analysis of ecological vulnerability and management in the Tarim River Basin, China. Science of the Total Environment, 649, 876-888.

Yan, W., Zhang, X.Z., Shi, P.L., Yang, Z.L., He, Y.T., Xu, L.L., 2006. Carbon dioxide exchange and water use efficiency of alpine meadow ecosystems on the Tibetan Plateau. Journal of Natural Resources, 21(5), 756-767.

Yang, B., Zuo, H.C., Dong, L.X., Yang, H.L., Chen, B.L., Dai, L.D., 2018. Impact of 687 observation error of desert underlying surface energy flux on energy closure in arid area. Arid Zone Research, 35(2), 452-460. 
dioxide exchange in paddy field ecosystem under water-saving irrigation in

691 Southeast China. Agricultural Water Management, 166, 42-52.

692 Yu, G.R., Fu, Y.L., Sun, X.M., Wen, X.F., Zhang, L.M., 2006. Recent progress and 693 future directions of ChinaFLUX. Science in China Series D: Earth Sciences, 49(2 694 Supplement), 1-23.

695 Yu, G.R., Song, X., Wang, Q.F., Liu, Y., Guan, D., Yan, J., Sun, X.M., Zhang, L.M., 696 Wen, X. F., 2008. Water-use efficiency of forest ecosystems in eastern China and 697 its relations to climatic variables. New phytologist, 177, 927-937.

698 Sun, G., Noormets, A., Gavazzi, M.J., Mcnulty, S.G., Chen, J., Domec, J.C., King, J.S., 699 Amatya, D.M., Skaggs, R.W., 2010. Energy and water balance of two contrasting 700 loblolly pine plantations on the lower coastal plain of North Carolina, USA. Forest $701 \quad$ Ecol. Manag., 259, 1299-1310.

702 Zanotelli, D., Montagnani, L., Manca, G., Tagliavini, M., 2013. Net primary 703 productivity, allocation pattern and carbon use efficiency in an apple orchard 704 assessed by integrating eddy covariance, biometric and continuous soil chamber 705 measurements, Biogeosciences, 10, 3089-3108.

706 Zhang, F.M., Ju, W.M., Shen, S.H., Wang, S.Q., Yu, G.R., Han, S.J., 2014. How recent 707 climate change influence water use efficiency in East Asia. Theoretical and $708 \quad$ Applied Climatology, 116, 359-370.

709 Zhao, F.H., Yu, G.R., Li, S.G., Ren, C.Y., Sun, X.M., Mi, N., Li, J., Zhu, O.Y., 2007. 710 Canopy water use efficiency of winter wheat in the North China Plain. 711 Agricultural Water Management, 93(3), 99-108.

712 Zhao, X.S., Liu, Y.B., 2018. Variability of surface heat fluxes and its driving forces at 713 different time scales over a large ephemeral lake in China. Journal of Geophysical 714 Research: Atmospheres, 123, 4939-4957.

715 Zhu, B.L., Xue, L.Q., Wei, G.H., Zhang, L.C., Chen, X.F., 2018. CMIP5 projected 716 changes in temperature and precipitation in arid and humid basins. Theoretical and 717 Applied Climatology, 136, 1133-1144. 


\section{Figures}

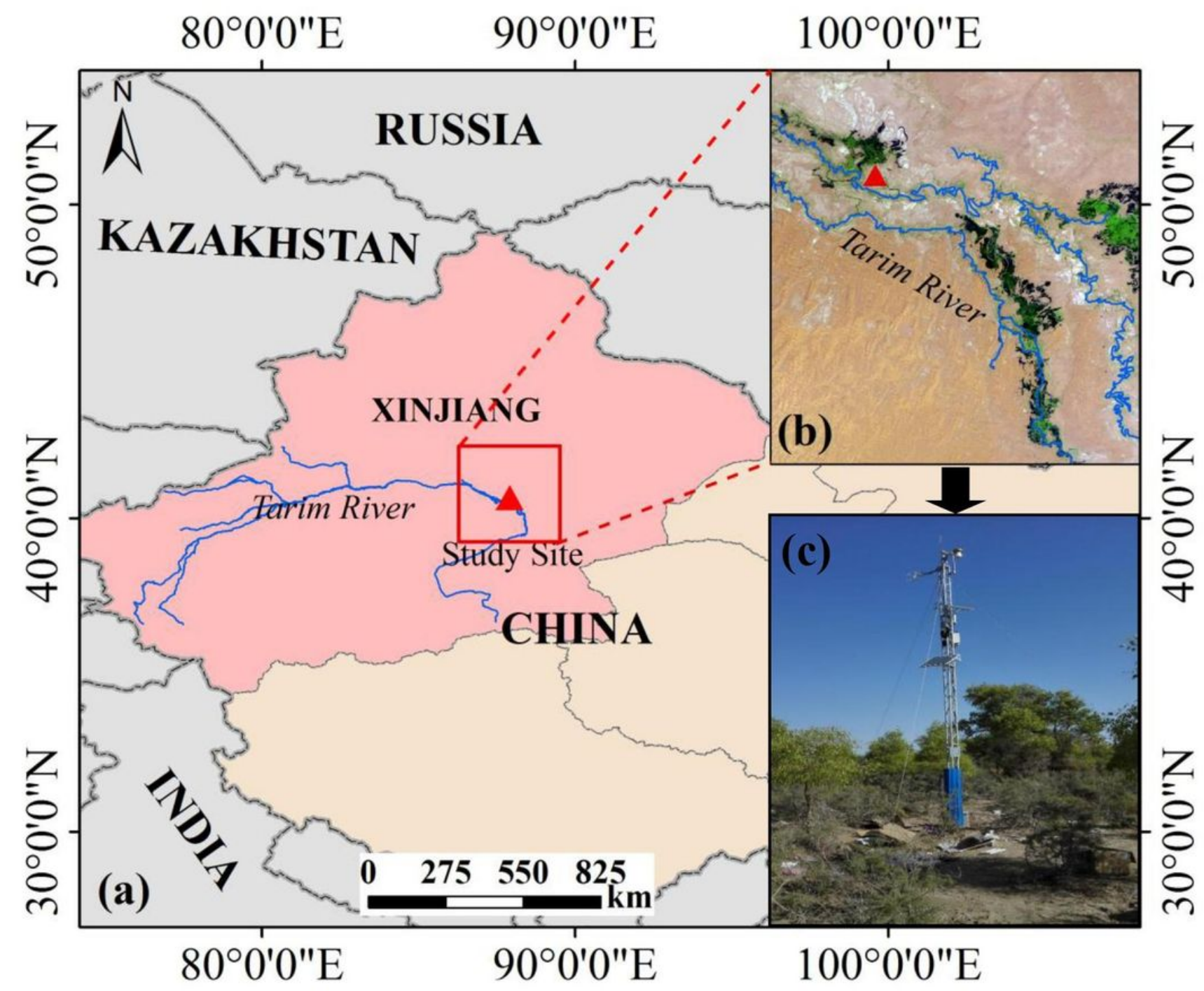

Figure 1

Location of the study area and images of the observation instruments. (a) Geographical location of the study site (red triangle), (b) remote sensing image of the study site and (c) erection of experimental instruments. Note: The designations employed and the presentation of the material on this map do not imply the expression of any opinion whatsoever on the part of Research Square concerning the legal status of any country, territory, city or area or of its authorities, or concerning the delimitation of its frontiers or boundaries. This map has been provided by the authors. 


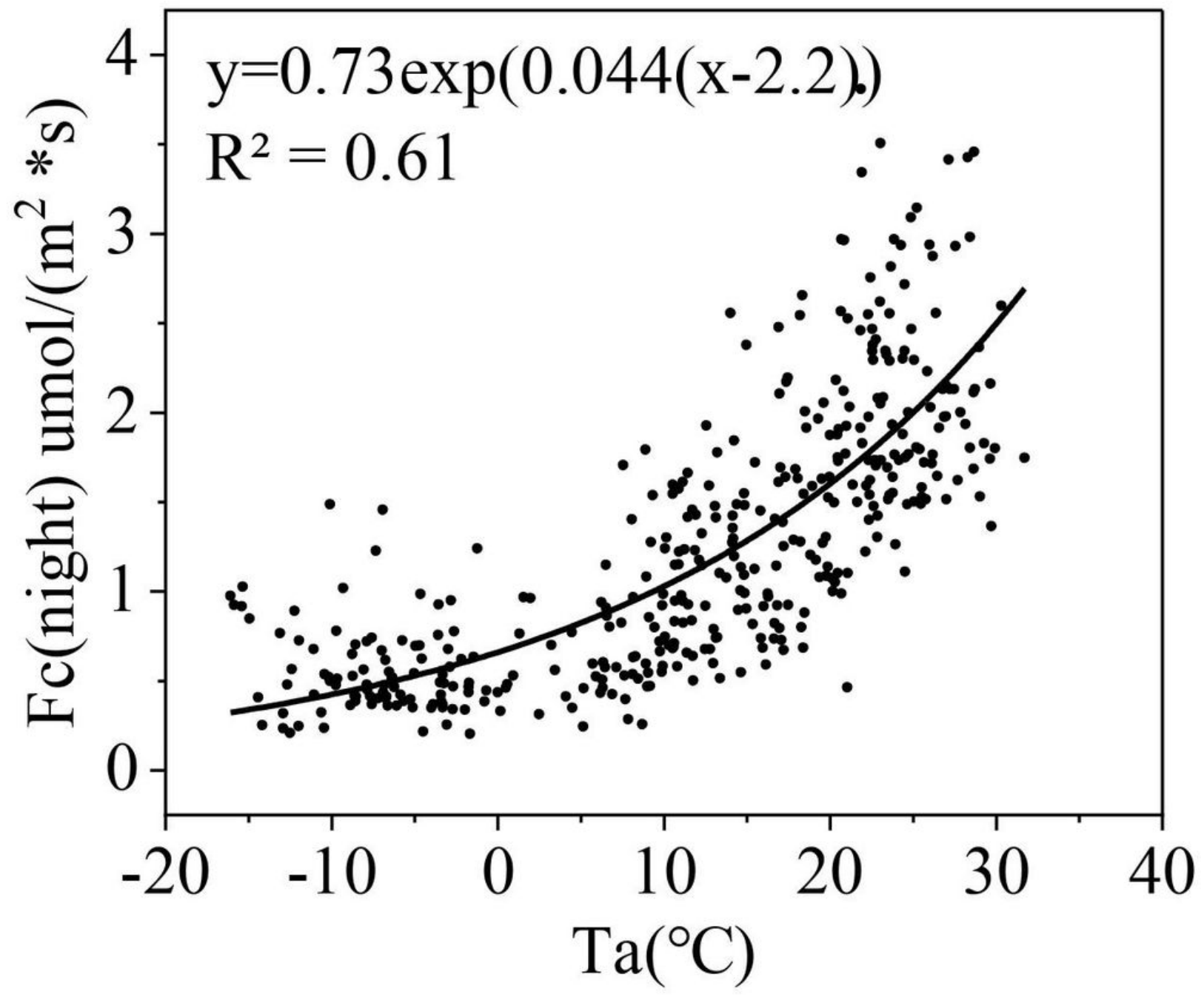

Figure 2

The relationship between $\mathrm{CO} 2$ flux at night (Fc(night)) and air temperature (Ta). The downward shortwave radiation (DR) is used as an indicator to distinguish daytime and nighttime. It is generally considered that when $\mathrm{DR}<1 \mathrm{~W} / \mathrm{m} 2$, the corresponding period is nighttime. 

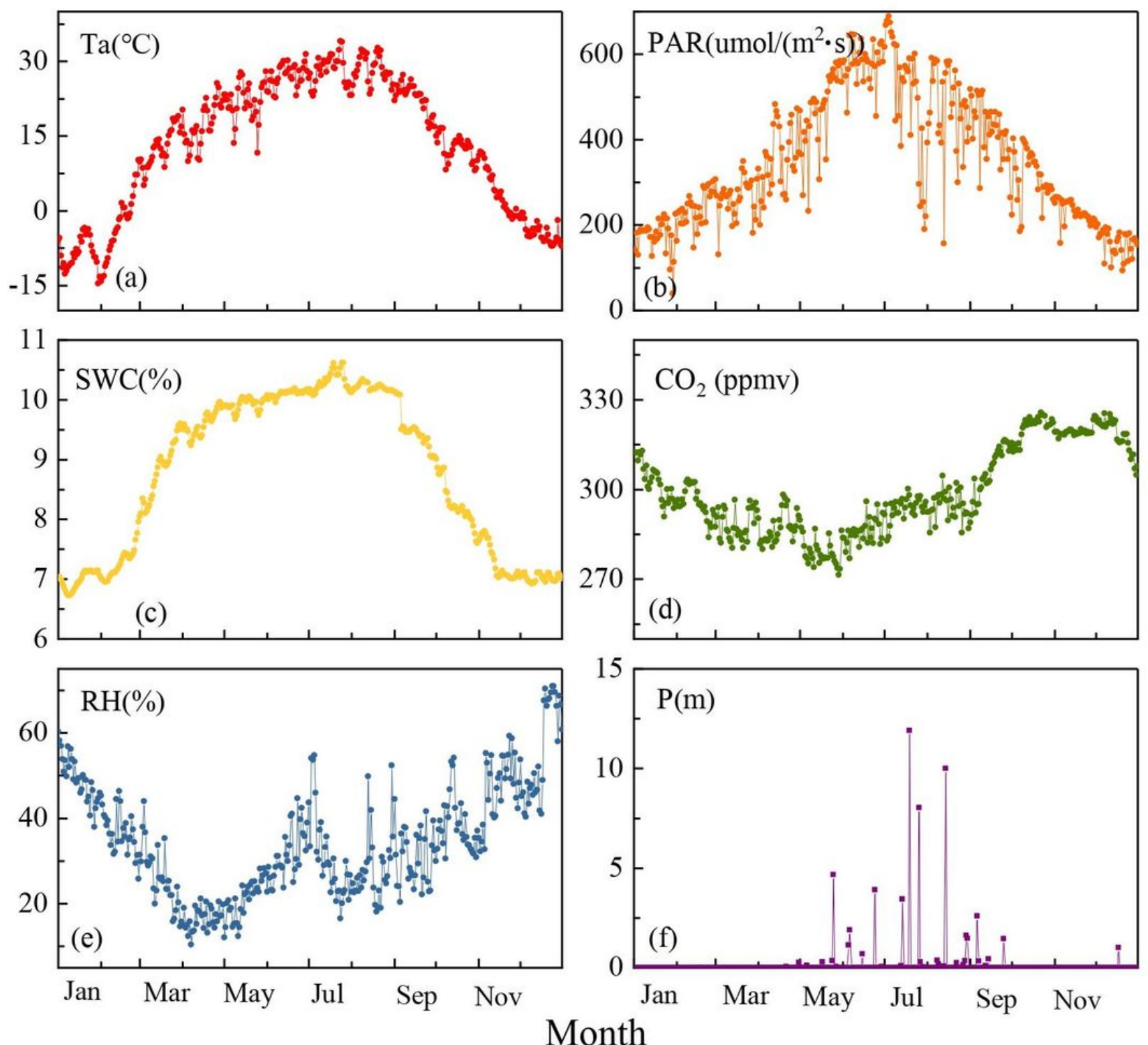

Figure 3

Seasonal variations in the daily mean environmental factors in 2018. (a) daily mean air temperature (Ta), (b) daily mean photosynthetically active radiation (PAR), (c) daily mean soil water content (SWC) at 20 $\mathrm{cm}$, (d) daily mean $\mathrm{CO} 2$ concentration, (e) daily mean air relative humidity $(\mathrm{RH}),(\mathrm{f})$ daily precipitation $(\mathrm{P})$. 

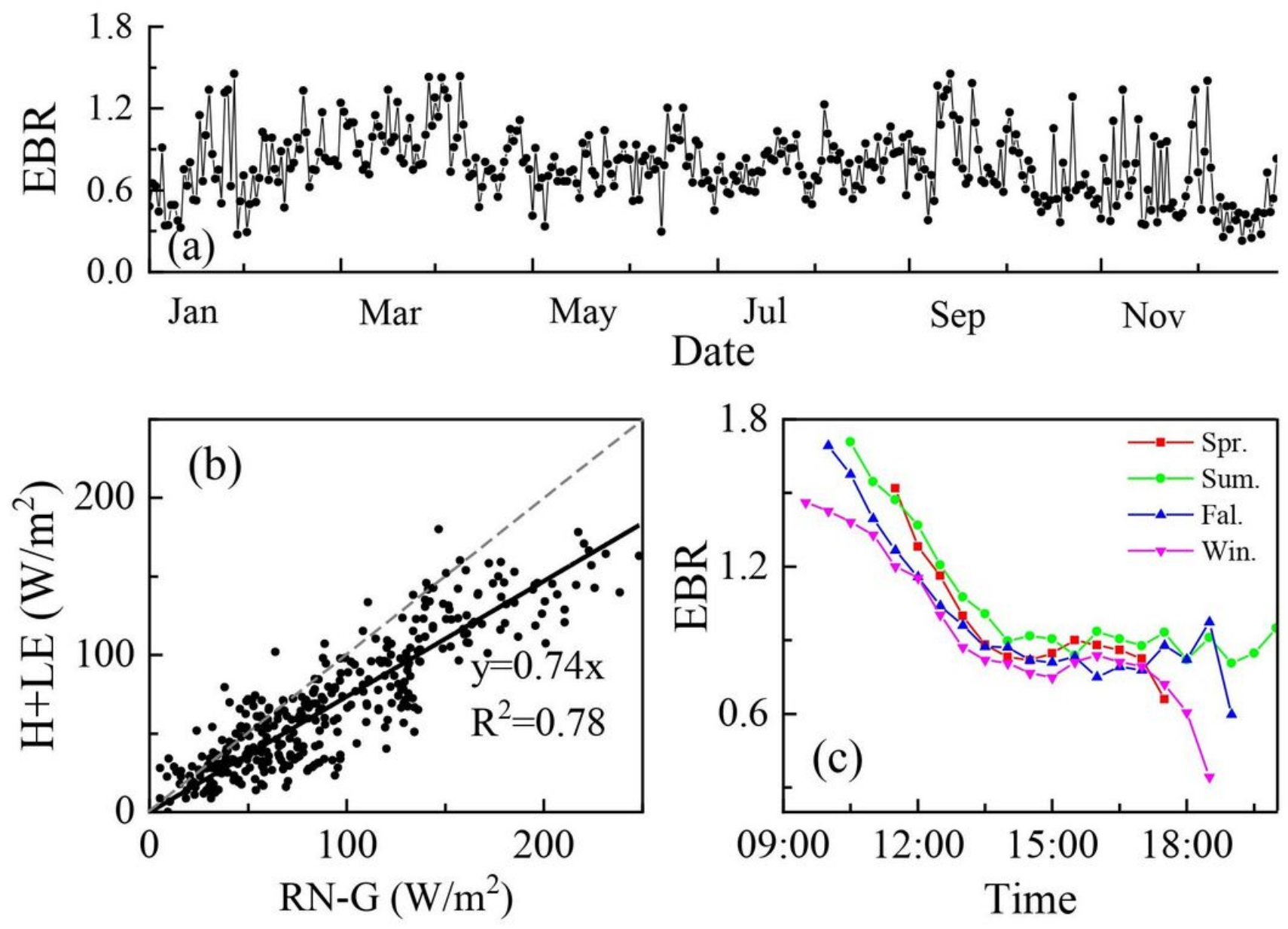

Figure 4

(a) Daily mean EBR in 2018, (b) relationship between the turbulent flux (H+LE) and available energy (RN$\mathrm{G})$, (c) diurnal changes of EBR in different seasons. The EBR was not meaningful during the morning and evening transition periods when the mean value of RN-G is close to zero. 

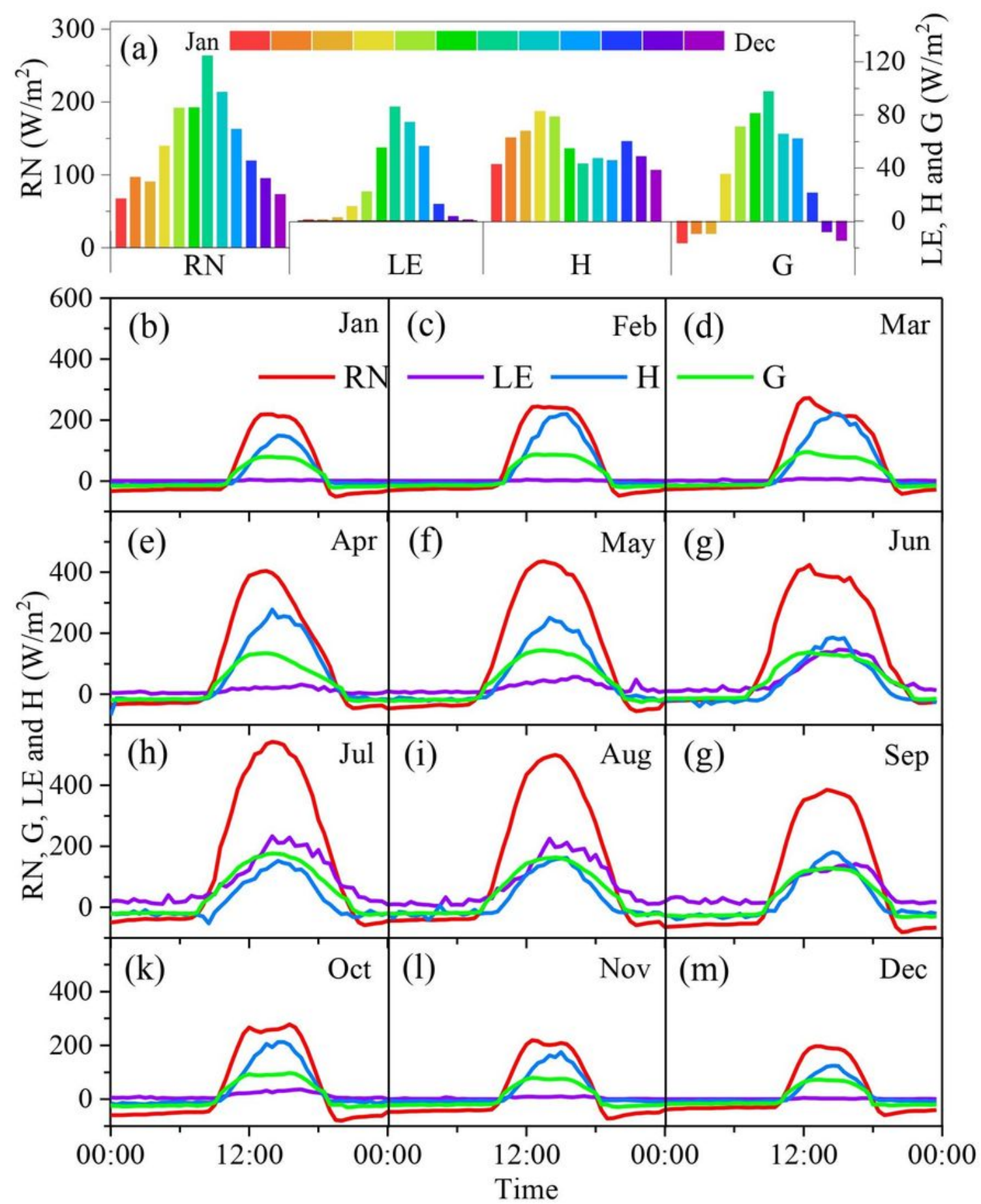

Figure 5

Variations of net radiation (RN), soil heat flux (G), latent heat flux (LE), and sensible heat flux $(H)$ in 2018. (a) Monthly variations in energy fluxes, (b)-( $\mathrm{m}$ ) diurnal variations in energy fluxes in different seasons. 

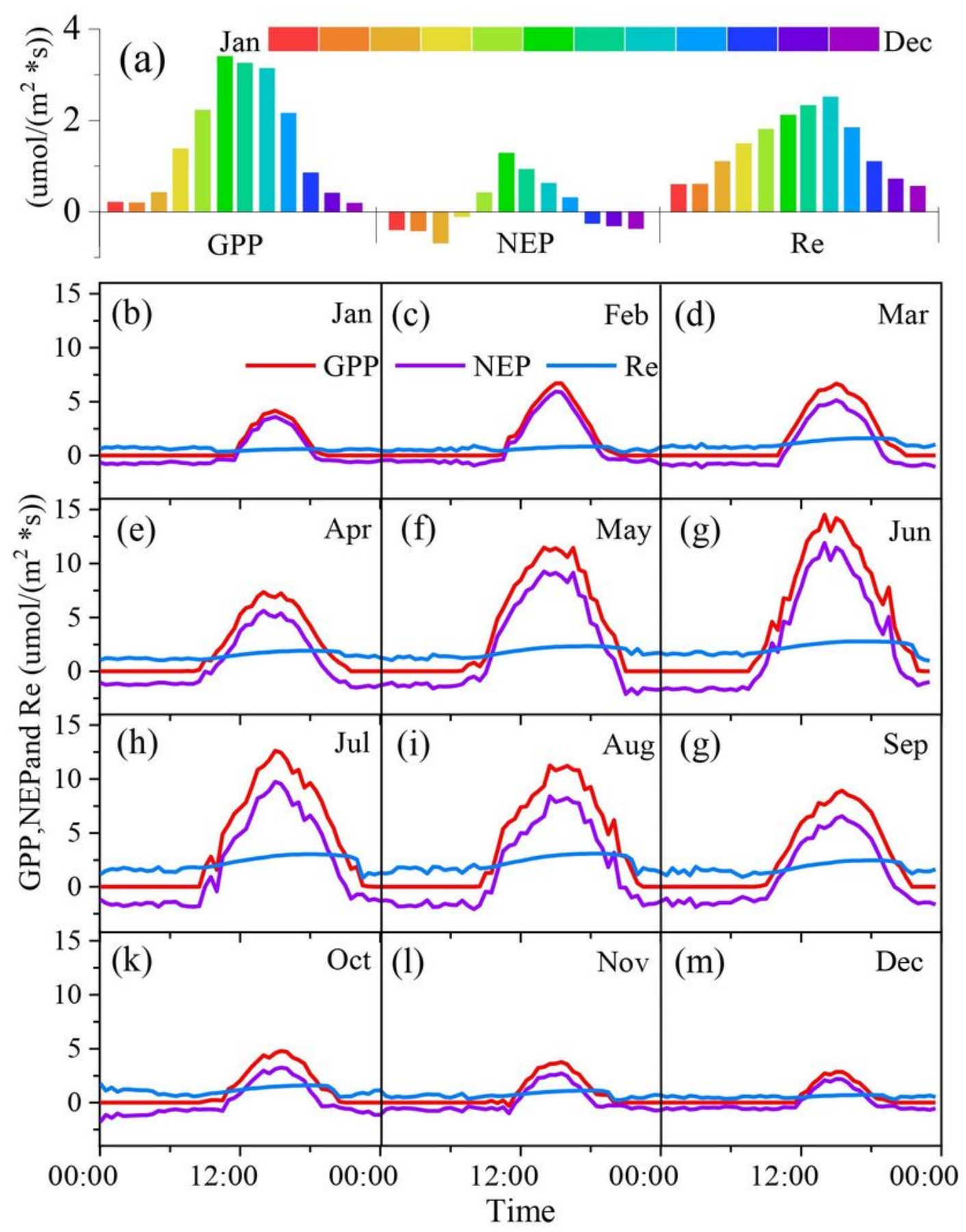

Figure 6

Variations of gross primary productivity (GPP), net ecosystem productivity (NEP), and total respiration $(\mathrm{Re})$ in 2018. (a) Monthly variations, (b)-(m) diurnal variations. 


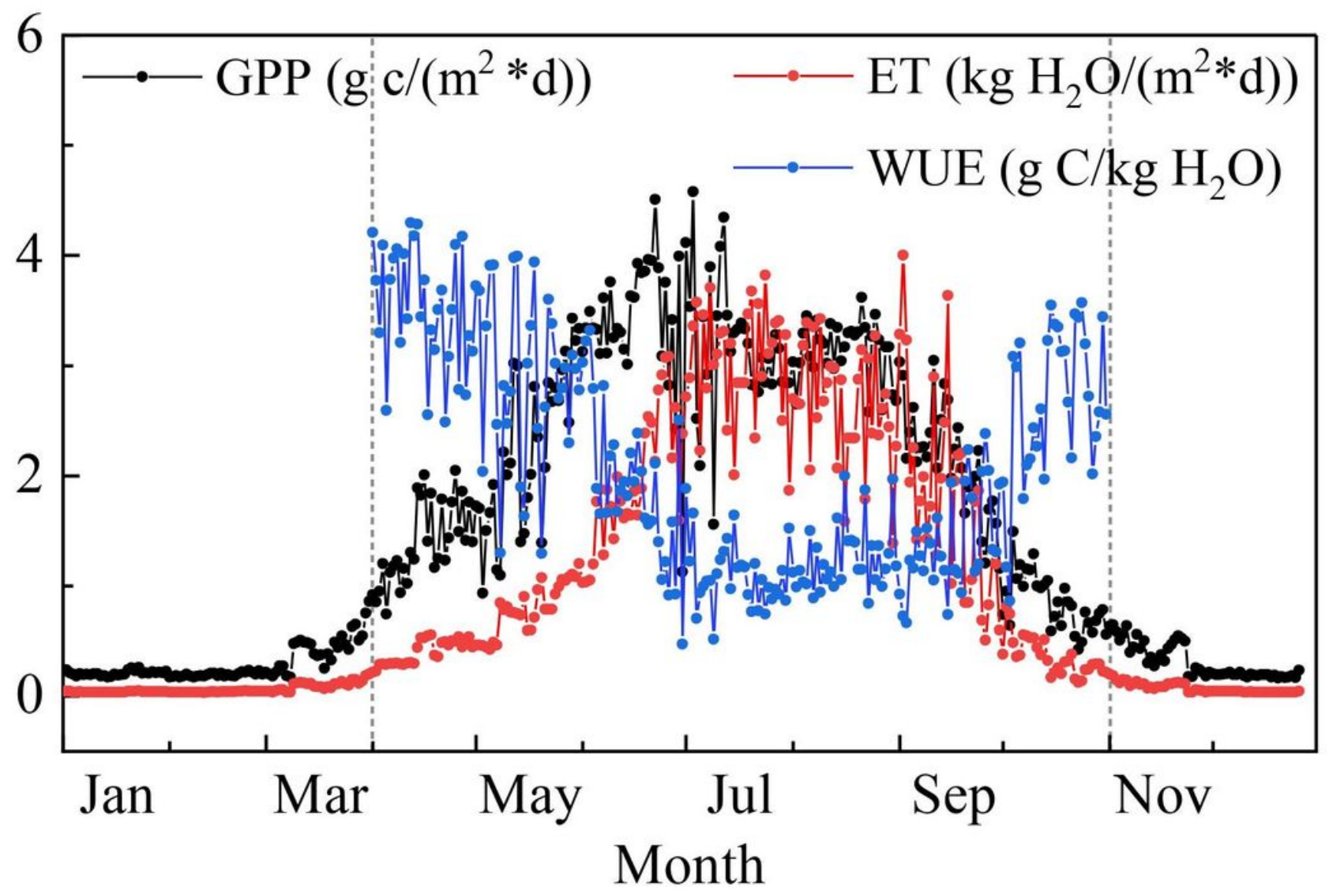

Figure 7

Daily mean gross primary productivity (GPP), evapotranspiration (ET) and water use efficiency (WUE) during the growing seasons (April-October) in 2018. 


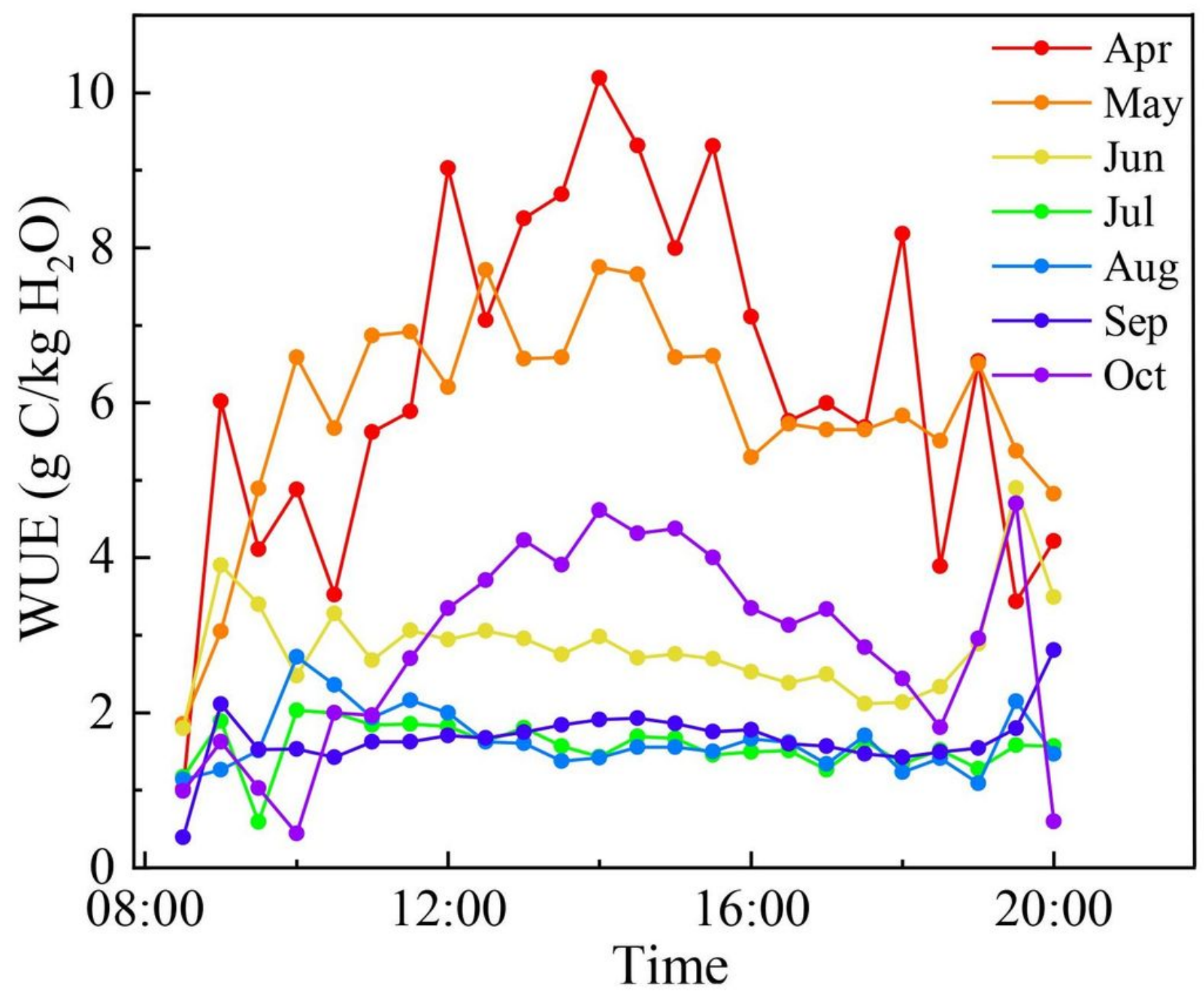

Figure 8

Diurnal water use efficiency (WUE) during the growing seasons (April-October) in 2018. 

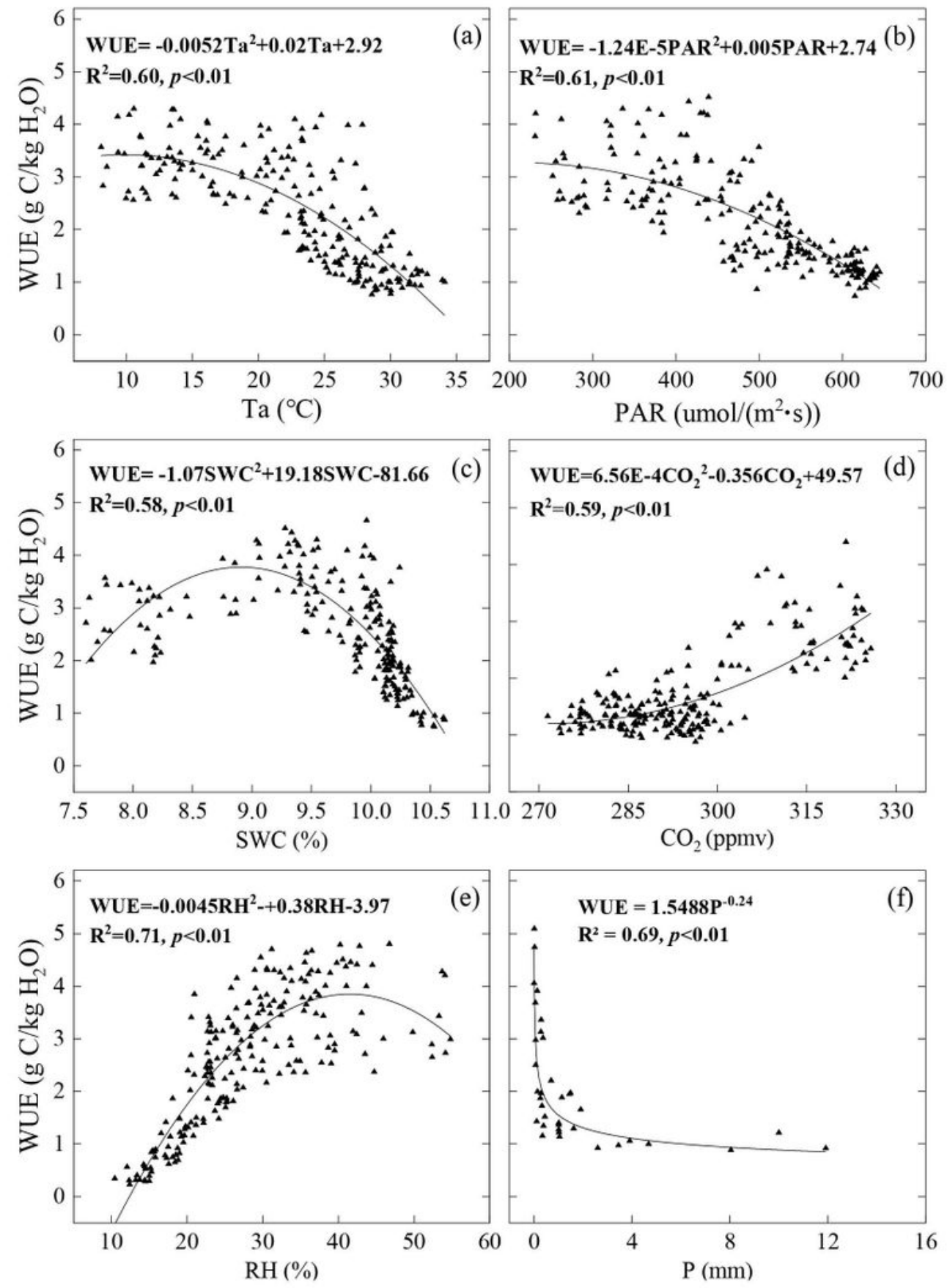

\section{Figure 9}

Relationship between water use efficiency (WUE) and (a) air temperature (Ta), (b) photosynthetically active radiation (PAR), (c) soil water content (SWC), (d) carbon dioxide concentration (CO2), (e) air relative humidity $(\mathrm{RH}),(\mathrm{f})$ precipitation $(\mathrm{P})$ during the growing seasons (April-October). 


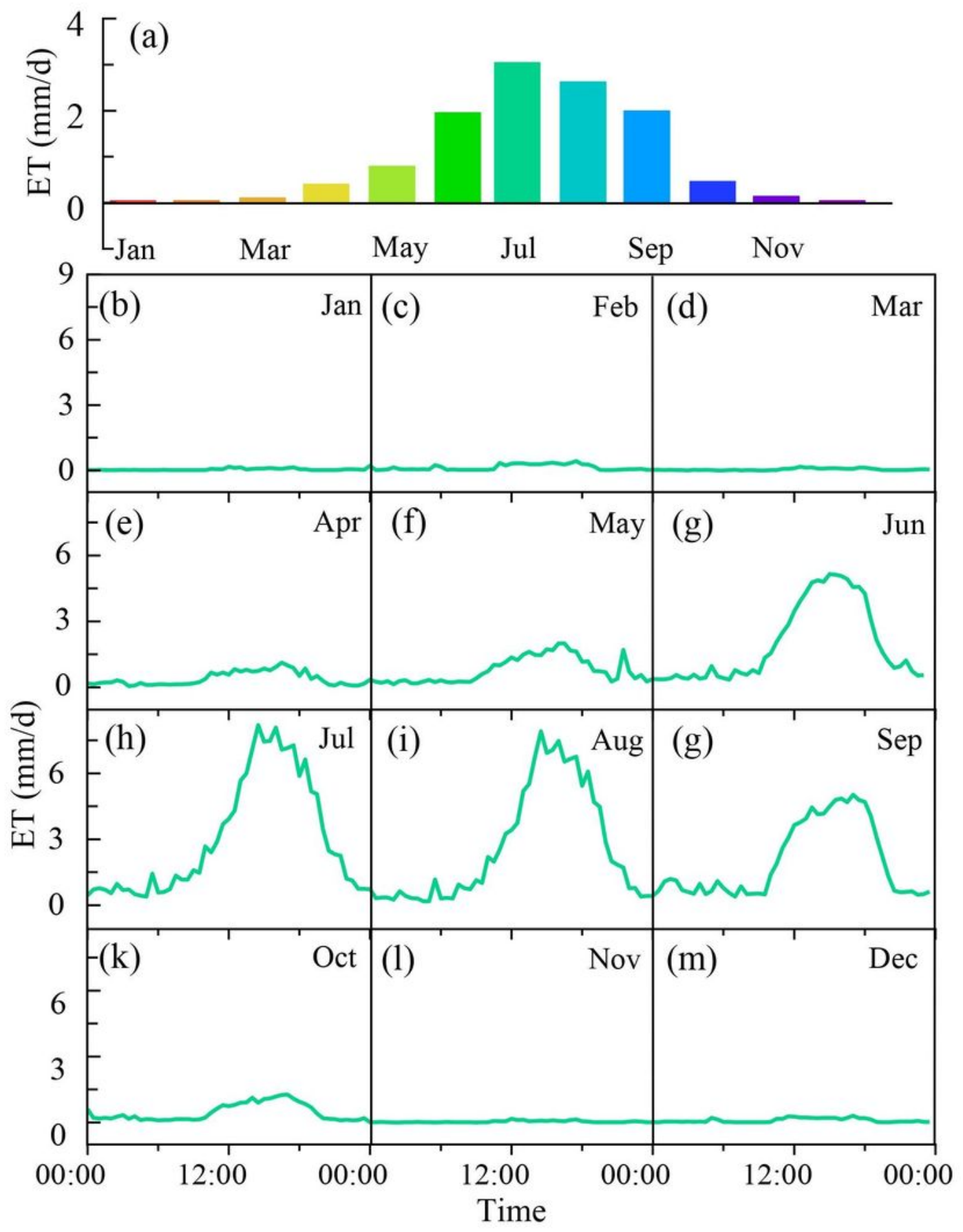

Figure 10

Variations of evapotranspiration (ET) in 2018. (a) Monthly variations, (b)-(m) diurnal variations. 


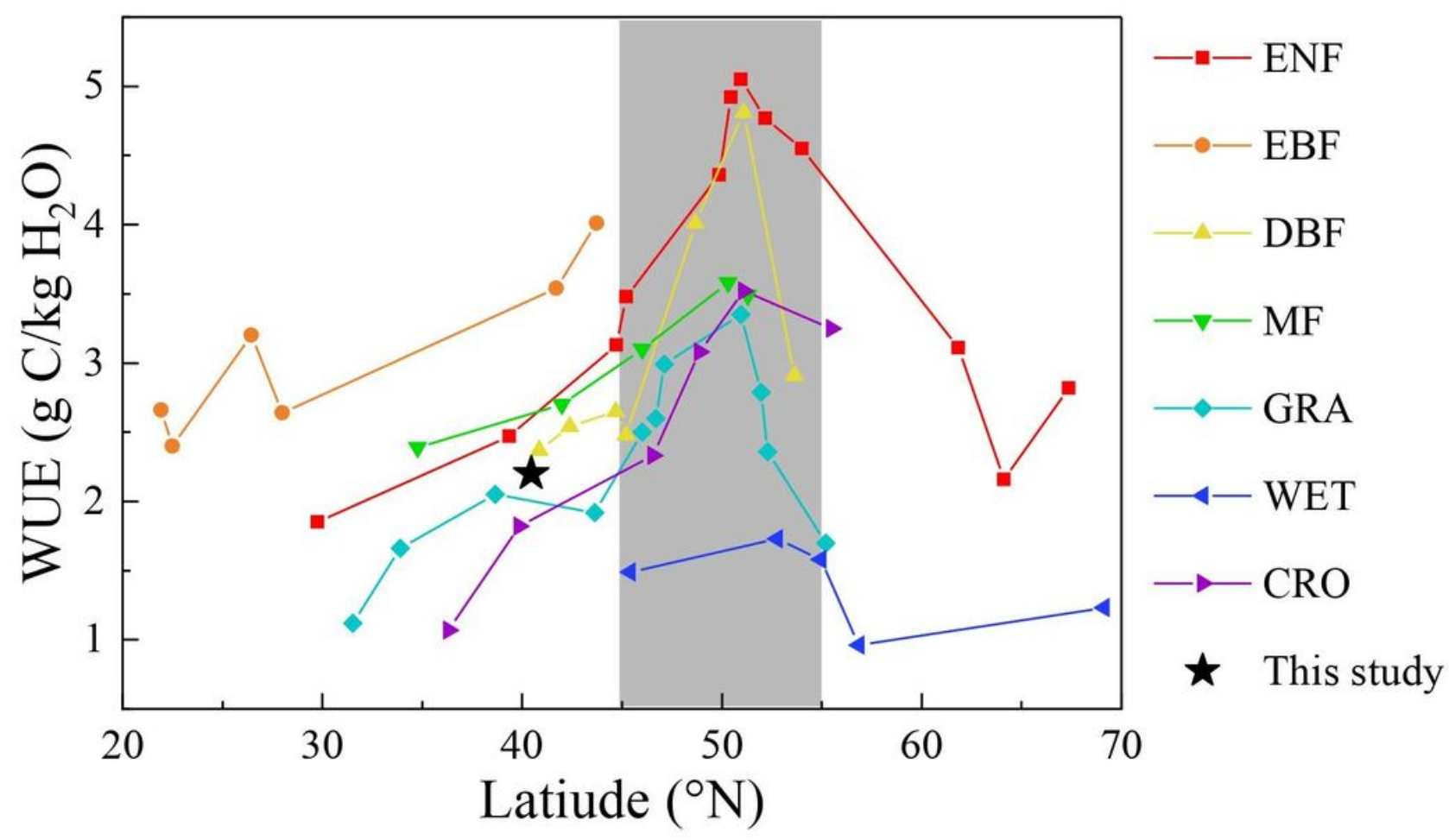

Figure 11

Latitudinal trends in multiyear mean annual WUE for different plant functional types. ENF, EBF, DBF, MF, GRA, WET and CRO represent evergreen needleleaf forest, evergreen broadleaved forest, deciduous broadleaved forest, mixed forest, grassland, wetland and cropland, respectively. References: Beer et al. [2009], Tang et al. [2014], Tan et al. [2014], Kwon et al. [2018], Quansah et al. [2015], Gang et al. [2016], Chatterjee et al. [2018] , Zanotelli et al. [2013]. 